\title{
Genetic Activation, Inactivation, and Deletion Reveal a Limited And Nuanced Role for Somatostatin-Containing Basal Forebrain Neurons in Behavioral State Control
}

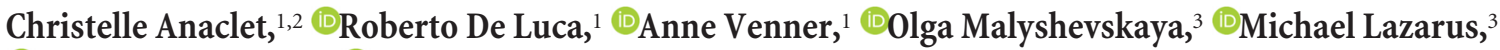 \\ (DE) Elda Arrigoni, ${ }^{1 \star}$ and $\mathbb{D}$ Patrick M. Fuller ${ }^{1 \star}$ \\ ${ }^{1}$ Department of Neurology, Beth Israel Deaconess Medical Center, Division of Sleep Medicine, Harvard Medical School, Boston, Massachusetts 02115, \\ ${ }^{2}$ Department of Neurobiology, University of Massachusetts Medical School, Worcester, Massachusetts 01605, and ${ }^{3}$ International Institute for Integrative \\ Sleep Medicine (WPI-IIIS), University of Tsukuba, Tsukuba, Ibaraki 305-8575, Japan
}

Recent studies have identified an especially important role for basal forebrain GABAergic $\left(\mathrm{BF}^{\mathrm{VGAT}}\right)$ neurons in the regulation of behavioral waking and fast cortical rhythms associated with cognition. However, $\mathrm{BF}^{\mathrm{VGAT}}$ neurons comprise several neurochemically and anatomically distinct subpopulations, including parvalbumin-containing $\mathrm{BF}^{\mathrm{VGAT}}$ neurons and somatostatin-containing $\mathrm{BF}^{\mathrm{VGAT}}$ neurons ( $\mathrm{BF}^{\mathrm{SOM}}$ neurons), and it was recently reported that optogenetic activation of $\mathrm{BF}^{\mathrm{SOM}}$ neurons increases the probability of a wakefulness to non-rapid-eye movement (NREM) sleep transition when stimulated during the rest period of the animal. This finding was unexpected given that most $\mathrm{BF}^{\text {SOM }}$ neurons are not NREM sleep active and that central administration of the synthetic somatostatin analog, octreotide, suppresses NREM sleep or increases REM sleep. Here we used a combination of genetically driven chemogenetic and optogenetic activation, chemogenetic inhibition, and ablation approaches to further explore the in vivo role of $\mathrm{BF}^{\mathrm{SOM}}$ neurons in arousal control. Our findings indicate that acute activation or inhibition of $\mathrm{BF}^{\mathrm{SOM}}$ neurons is neither wakefulness nor NREM sleep promoting and is without significant effect on the EEG, and that chronic loss of these neurons is without effect on total $24 \mathrm{~h}$ sleep amounts, although a small but significant increase in waking was observed in the lesioned mice during the early active period. Our in vitro cell recordings further reveal electrophysiological heterogeneity in $\mathrm{BF}^{\mathrm{SOM}}$ neurons, specifically suggesting at least two distinct subpopulations. Together, our data support the more nuanced view that $\mathrm{BF}^{\mathrm{SOM}}$ neurons are electrically heterogeneous and are not NREM sleep or wake promoting per se, but may exert, in particular during the early active period, a modest inhibitory influence on arousal circuitry.

Key words: AAV; arousal; diphtheria; DREADD; EEG; optogenetic

\section{Significance Statement}

The cellular basal forebrain (BF) is a highly complex area of the brain that is implicated in a wide range of higher-level neurobiological processes, including regulating and maintaining normal levels of electrocortical and behavioral arousal. The respective in vivo roles of BF cell populations and their neurotransmitter systems in the regulation of electrocortical and behavioral arousal remains incompletely understood. Here we seek to define the neurobiological contribution of GABAergic somatostatincontaining BF neurons to arousal control. Understanding the respective contribution of BF cell populations to arousal control may provide critical insight into the pathogenesis of a host of neuropsychiatric and neurodegenerative disorders, including Alzheimer's disease, Parkinson's disease, schizophrenia, and the cognitive impairments of normal aging.

\section{Introduction}

An important, if indispensable, role for the cellular basal forebrain (BF) in behavioral and electrocortical arousal has been pre- viously established, in particular for BF GABAergic (BF ${ }^{\mathrm{VGAT}}$ ) neurons (Buzsaki et al., 1988; Fuller et al., 2011; Anaclet et al., 2015; Kim et al., 2015; Xu et al., 2015). For example, acute che-
Received Oct. 13, 2017; revised March 26, 2018; accepted April 24, 2018.

Author contributions: C.A., R.D.L., A.V., E.A., and P.M.F. designed research; C.A., R.D.L., and A.V. performed research; 0.M., M.L., E.A., and P.M.F. contributed unpublished reagents/analytic tools; C.A., R.D.L., A.V., E.A., and P.M.F. analyzed data; C.A., R.D.L., A.V., E.A., and P.M.F. wrote the paper.

This work was supported by National Institutes of Health Grants K99-MH-103399 and R00-MH-103399 (C.A.); NS-073613, NS-092652, and NS-103161 (P.M.F.); and NS-091126 (E.A.). We thank Tilar Martin, Rebecca Broadhurst, Lauren Sohn, Minh Ha, and Quan Hue Ha for technical assistance.
*E.A. and P.M.F. are co-senior authors.

Correspondence should be addressed to either of the following: Elda Arrigoni, Department of Neurology, Beth Israel Deaconess Medical Center, 330 Brookline Avenue, E/CLS 705, Boston, MA 02215, E-mail: earrigon@bidmc.harvard.edu; or Patrick M. Fuller, Department of Neurology, Beth Israel Deaconess Medical Center, 330 Brookline Avenue, E/CLS 707, Boston, MA 02215, E-mail: pfuller@bidmc.harvard.edu.

DOI:10.1523/JNEUROSCI.2955-17.2018

Copyright $\odot 2018$ the authors $\quad 0270-6474 / 18 / 385168-14 \$ 15.00 / 0$ 
mogenetic and optogenetic activation of $\mathrm{BF}^{\mathrm{VGAT}}$ neurons, including those containing the calcium binding protein parvalbumin $\left(\mathrm{Parv}^{+}\right)$, rapidly induces behavioral waking and fast cortical rhythms associated with cognition (Anaclet et al., 2015; Kim et al., 2015; Xu et al., 2015). By contrast, acute chemogenetic inhibition of $\mathrm{BF}^{\mathrm{VGAT}}$ neurons during the early subjective night (active period) increases non-rapid-eye movement (NREM) sleep and cortical slow-wave activity (Anaclet et al., 2015). Hence, BF ${ }^{\text {VGAT }}$ neurons appear to be both sufficient and necessary for normal behavioral and EEG wakefulness (W). However, the BF contains several neurochemically and anatomically distinct subpopulations of $\mathrm{BF}^{\mathrm{VGAT}}$ neurons beyond $\mathrm{Parv}^{+}$, including a population of $\mathrm{BF}^{\mathrm{VGAT}}$ neurons that contain the neuropeptide somatostatin $\left(\mathrm{BF}^{\mathrm{SOM}}\right.$; Yang et al., 2017). Interestingly, $\mathrm{BF}^{\mathrm{SOM}}$ and $\mathrm{BF}^{\text {Parv }}$ neurons derive from the same embryonic progenitors, raising the possibility that $\mathrm{BF}^{\mathrm{SOM}}$ neurons may contribute to the wakepromoting and EEG-activating responses seen following the activation of $\mathrm{BF}^{\text {Parv }}$ neurons ( $\mathrm{Hu}$ et al., 2013). This possibility, however, seems unlikely given findings from a recent study that showed that optogenetic stimulation of $\mathrm{BF}^{\mathrm{SOM}}$ neurons increased the probability of a wakefulness to NREM sleep transition, and not a NREM to wakefulness transition, during the normal rest period of the animal (Xu et al., 2015). Yet it remains a challenge to reconcile a NREM sleep-promoting role for $\mathrm{BF}^{\mathrm{SOM}}$ neurons given that the majority of $\mathrm{BF}^{\mathrm{SOM}}$ neurons are not NREM sleep active (Xu et al., 2015) and that the administration of octreotide, a synthetic SOM analog, was found to either suppress NREM sleep or increase rapid-eye movement (REM) sleep in rats (Hajdu et al., 2003; Ziegenbein et al., 2004) and impairs deep sleep in humans (Ziegenbein et al., 2004). Moreover, a role for $\mathrm{BF}^{\mathrm{SOM}}$ neurons in feeding and anxiety, both of which are wakingrelated behaviors, has been described recently (Zhu et al., 2017). Perhaps most importantly, key evidence for a sleep- or wakepromoting role for $\mathrm{BF}^{\mathrm{SOM}}$ neurons, taking the form of a loss of function (acute inhibition or chronic loss) experiments, is lacking.

Hence, and building upon on prior experimental work that established a key regulatory role for $\mathrm{BF}^{\mathrm{VGAT}}$ neurons in neurobehavioral and electrocortical arousal (Anaclet et al., 2015), we used a combination of genetically driven chemogenetic and optogenetic activation, chemogenetic inhibition, and ablation approaches to more definitively assess the in vivo role of $\mathrm{BF}^{\mathrm{SOM}}$ neurons, as a genetically defined subgroup of BF ${ }^{\mathrm{VGAT}}$ neurons (Yang et al., 2017), in sleep-wake regulation.

\section{Materials and Methods}

Animals. Adult male and female SOM-ires-Cre mice (age, 8-12 weeks; weight, $20-25 \mathrm{~g} ; n=42$ in vivo; $n=11$ in vitro), obtained from The Jackson Laboratory, were used in this study. The SOM-ires-Cre (or SstIRES-Cre knock-in allele) has an internal ribosome entry site and Cre recombinase in the $3^{\prime}$ UTR of the somatostatin locus (Sst). These mice have been used and histologically validated in a previous study (Xu et al., 2015). All mice were bred at our animal facility and underwent genotyping both before and after experiments, and all procedures were approved by the Institutional Animal Care and Use Committee of Beth Israel Deaconess Medical Center.

Surgery. Mice were anesthetized with ketamine/xylazine (100 and 10 $\mathrm{mg} / \mathrm{kg}$, i.p., respectively) and then placed in a stereotaxic apparatus. To selectively express the hM3Dq receptors in GABAergic somatostatinexpressing $\left(\mathrm{SOM}^{+}\right)$neurons of the BF (diagonal band, magnocellular preoptic nucleus, and ventral regions of the substantia innominata and ventral pallidum), we placed bilateral injections of an adeno-associated viral (AAV; serotype 10) vector expressing the hM3Dq receptor in a credependent configuration [hSyn-DIO-hM3Dq-mCherry-AAV (hM3Dq$\mathrm{AAV})$ ] into the $\mathrm{BF}$ [coordinates: anteroposterior $(\mathrm{AP})=+0.02 \mathrm{~mm}$; lateral
$(\mathrm{L})= \pm 1.45 \mathrm{~mm}$; dorsoventral $(\mathrm{DV})=-4.80 \mathrm{~mm}$ (as per the mouse atlas of Paxinos and Franklin, 2001)] of homozygous SOM-ires-Cre (BF ${ }^{\text {SOM-hM3Dq, }}$ $n=8$ ). To selectively express the hM4Di receptors in $\mathrm{SOM}^{+}$neurons of the magnocellular BF, we placed bilateral injections of an AAV (serotype 10) vector expressing the hM4Di receptor in a cre-dependent configuration [hSyn-DIO-hM4Di-mCherry-AAV (hM4Di-AAV)] into the BF of heterozygous SOM-ires-Cre, lox-L10GFP ( $\left.\mathrm{BF}^{\text {SOM-hM4Di }}, n=5\right)$ mice. To selectively kill $\mathrm{SOM}^{+}$neurons of the magnocellular BF, we placed bilateral injections of an AAV (serotype 10) vector expressing the diphtheria toxin subunit A (DTA) in a cre-dependent configuration [hSyn-DIO-DTAmCherry-AAV (DTA-AAV)] into the BF of heterozygous SOM-ires-Cre, lox-L10GFP (BF $\left.{ }^{\text {SOM-DTA }}, n=11\right)$ mice. A vector injection control [hSynDIO-mCherry-AAV (mCherry-AAV)] was placed into the BF of littermate heterozygous SOM-ires-Cre, lox-L10GFP mice (BF ${ }^{\text {SOM-mCherry }}, n=5$ ). Injections of hM3Dq-AAV, hM4Di-AAV, or DTA-AAV (60 nl) into the $\mathrm{BF}$ of these mice were performed using a compressed air delivery system as described previously (Fuller et al., 2011). The scalp wound was closed with surgical sutures, and the mouse was kept in a warm environment until resuming normal activity, as described previously. In a separate surgery taking place at least 2 weeks after brain injection, mice were implanted with four EEG screw electrodes (two frontal and two parietal electrodes; catalog \#8403, Pinnacle Technology) and two flexible electromyogram (EMG) wire electrodes (catalog \#E363/76/SPC, Plastics One) previously soldered to a six-pin connector (catalog \#853-43-006-10001000, Heilind Electronics), and the assembly was secured with dental cement (Anaclet et al., 2014). The frontal electrodes were positioned 1 $\mathrm{mm}$ frontal and $1 \mathrm{~mm}$ lateral of bregma, whereas the parietal electrodes were positioned $1 \mathrm{~mm}$ lateral from bregma and midway between bregma and lambda. For the in vivo optogenetic experiments, SOM-ires-Cre $\left(\mathrm{BF}^{\mathrm{SOM}-\mathrm{ChR} 2}, n=11\right)$ and VGAT-ires-Cre $\left(\mathrm{BF}^{\mathrm{Vgat}-\mathrm{ChR} 2}, n=2\right)$ mice were stereotaxically injected with $60 \mathrm{nl}$ of AAV8-FLEX-EF1 $\alpha$-channelrhodopsin-2 (ChR2)-mCherry [bilateral: $(\mathrm{AP})=+0.02 \mathrm{~mm}$; lateral $(\mathrm{L})= \pm 1.45 \mathrm{~mm}$; dorsoventral $(\mathrm{DV})=-4.80 \mathrm{~mm}$ (as per the mouse atlas of Paxinos and Franklin, 2001)], and optical fibers [200 $\mu \mathrm{m}, 0.39$ numerical aperture (NA)] were implanted so that the fiber tip targeted a region $0.2 \mathrm{~mm}$ dorsal to the injection site (bilateral: $(\mathrm{AP})=+0.02 \mathrm{~mm}$; lateral $(\mathrm{L})= \pm 1.45 \mathrm{~mm}$; dorsoventral $(\mathrm{DV})=-4.40 \mathrm{~mm})$. Of the 11 $\mathrm{BF}^{\text {SOM-ChR2 }}$ mice, we excluded 4 mice, based upon histology, that showed caudal placement of fiber/injection. Our final analysis, therefore, includes $7 \mathrm{BF}^{\mathrm{SOM}-\mathrm{ChR} 2}$ mice that had good bilateral placement of the optical fibers and ChR2 expression within the BF. All mice were equipped with a headset for recording EEG/EMG, as previously described for chemogenetic experiments. Optical fibers and headset were secured in place first with a mixture of dental cement and cyanoacrylate glue to affix the hardware to the skull and second with dental cement alone to build a stable headcap and provide electrical insulation for the EEG/EMG headset.

Sleep-wake monitoring - chemogenetics. Two weeks after EEG/EMG implantation, the mice were housed individually in transparent barrels in an insulated sound-proofed recording chamber maintained at an ambient temperature of $22 \pm 1^{\circ} \mathrm{C}$ and on a $12 \mathrm{~h}$ light/dark cycle [lights on at 7:00 A.M.; or zeitgeber time 0 (ZT0)] with food and water available ad libitum. Mice were habituated to the recording cable for 5-7 d before starting a polygraphic recording. Cortical EEG (ipsilateral frontoparietal leads) and EMG signals were amplified and digitalized with a resolution of $500 \mathrm{~Hz}$ using VitalRecorder software (Kissei). BF SOM-DTA $^{\text {and }}$ $\mathrm{BF}^{\text {SOM-mCherry }}$ control mice were subjected to $48 \mathrm{~h}$ of baseline recording. $\left(\mathrm{BF}^{\text {SOM-hM3Dq }}\right.$ and $\mathrm{BF}^{\text {SOM-hM4Di }}$ mice were recorded for a $24 \mathrm{~h}$ baseline period followed by injections of clozapine- $N$-oxide (CNO; 0.3 and $0.9 \mathrm{mg} / \mathrm{kg}$ in saline, i.p.; Sigma-Aldrich) injections at 10:00 A.M. (or ZT3; light period, time of high sleeping drive) and 7:00 P.M. (or ZT12; lights-off, time of high activity). As control injections, mice were injected with saline at 10:00 A.M. and 7:00 P.M. CNO and saline injections were performed in a random sequence and separated by a 3-5 d washout period. The injections were performed using a crossover design. Data were scored off-line using SleepSign for Animals software (Kissei).

Sleep-wake monitoring - optogenetics. At least 2 weeks following optical fiber/EEG implant surgeries, mice were habituated to the recording chamber and recording equipment (electrical cables plus bilateral optical patch cables; $200 \mu \mathrm{m}, 0.39 \mathrm{NA}$ ) for $5 \mathrm{~d}$ before commencing the experi- 
ment. A $473 \mathrm{~nm}$ blue light (LASERGLOW Technologies) was used to activate ChR2 in BF neurons with an estimated power output at the tip of the optical fiber of 12-15 $\mathrm{mW}$. The stimulation paradigm consisted of 10 ms light pulses, delivered at a frequency of 2.5 or $10 \mathrm{~Hz}$ continuously, for $1 \mathrm{~min}$ every $10 \mathrm{~min}$ for a $3 \mathrm{~h}$ window during the light period (between 9:00 A.M. and 3:00 P.M.). Stimulations were controlled using the digital output of a Micro 1401-3 data acquisition unit and Spike version 2.08 software (Cambridge Electronic Design). Mice were given $1 \mathrm{~d}$ of recovery between each stimulation frequency. The electrical signal from the EEG/ EMG headset was amplified by 20,000 using an AM Systems Model 3500 amplifier and digitized at $500 \mathrm{~Hz}$ using the Micro 1401-3 unit. Data were scored off-line using Spike version 2.08 software.

$h M 3 D q / h M 4 D i-A A V$ and clozapine-N-oxide. For the in vivo and in vitro studies, we used evolved G-protein-coupled muscarinic receptors (hM3Dq and hM4Di) that are selectively activated by the pharmacologically inert drug CNO. This system was first developed and described by the Roth laboratory (Alexander et al., 2009). In our studies, cre-dependent versions of the hM3Dq and hM4Di receptors were packaged into an AAV to facilitate the stereotaxic-based delivery and regionally restricted expression of hM3Dq and hM4Di. As demonstrated previously by our laboratory (Anaclet et al., 2014, 2015, 2018; Venner et al., 2016; Pedersen et al., 2017) and others, both the hM3Dq/hM4Di receptors and ligand are biologically inert in the absence of ligand. Moreover, at the administered dose of $0.3 \mathrm{mg} / \mathrm{kg}$, CNO injection (1) does not affect sleep-wake quantity or quality in wild-type control mice and (2) induces a maximum effect during the $1-3 \mathrm{~h}$ postinjection period (Anaclet et al., 2014, 2018). We are therefore confident that the sleep-wake effects described in our studies result from specific activation or inhibition of the targeted neuronal population and not from a nonspecific effect of $\mathrm{CNO}$ or its metabolite clozapine (Gomez et al., 2017).

Sleep scoring and analysis. Using SleepSign for Animal (Kissei) and with the assistance of spectral analysis using fast Fourier transform (FFT), polygraphic records were visually scored by $10 \mathrm{~s}$ epochs for $\mathrm{W}$, NREM sleep, and REM sleep. The percentage of time spent in W, NREM sleep, and REM sleep, as well as the number and the average durations of the episode were summarized for each group and each condition. The latency to NREM sleep and REM sleep are defined as the time between the end of the injection and the onset of the first NREM sleep episode lasting $>20 \mathrm{~s}$ and the first REM sleep episode lasting $>10 \mathrm{~s}$.

Recordings were scored again in $5 \mathrm{~s}$ epochs to allow for the performance of an EEG power spectrum analysis, during the $3 \mathrm{~h}$ postinjection, when the effect of CNO is at its maximum (Anaclet et al., 2014, 2015). On the basis of visual and spectral analysis, epochs containing artifacts occurring during active wakefulness (with large movements) or containing two vigilance states were visually identified and omitted from the spectral analysis. Recordings containing wake artifact during $>20 \%$ of the time were removed from the spectral analysis. EEG power spectra were computed for consecutive $5 \mathrm{~s}$ epochs within the frequency range of $0.5-120$ $\mathrm{Hz}$ using an FFT routine. The data were collapsed into $0.5 \mathrm{~Hz}$ bins. The data were standardized by either expressing each frequency bin as a percentage relative to the total power (e.g., bin power/total power: $0.5 / 120$ $\mathrm{Hz}$ ) of the same epochs; or expressing each frequency bin as a percentage relative to the same bin in baseline condition from the same mouse and from the same time of the day (same zeitgeber time). To analyze the EEG frequency bands, relative power bins were summed in delta $(\delta, 0.5-5 \mathrm{~Hz})$, theta $(\theta, 5-9 \mathrm{~Hz})$, sigma $(\sigma, 9-15 \mathrm{~Hz})$, beta $(\beta, 15-30 \mathrm{~Hz})$, low gamma $(\mathrm{l} \gamma, 30-60 \mathrm{~Hz})$, and high gamma $(\mathrm{h} \gamma, 60-120 \mathrm{~Hz})$.

The individuals performing the saline/CNO injections and sleep-wake analysis were blinded to the initial immunohistochemical assessment of the injection sites.

Statistical analysis. Statistical analysis was performed using Prism version 6 (GraphPad Software). Following confirmation that the data met the assumptions of the ANOVA model, a two-way ANOVA followed by a post hoc Bonferroni test were used to compare the effects of the genotype or the drug injection on sleep-wake parameters. One-way ANOVA was used to analyze the latency to NREM sleep or REM sleep. Sample size and power calculations were performed post hoc at http://www.biomath. info, using means and SDs derived from our analysis. The present study was sufficiently powered to detect effect sizes.
Immunohistochemistry. Animals received $\mathrm{CNO}(0.3 \mathrm{mg} / \mathrm{kg}$, i.p., at 10:00 A.M.) and were killed $2 \mathrm{~h}$ later by deep anesthesia with $200 \mathrm{mg} / \mathrm{kg}$ chloral hydrate, followed by transcardial perfusion with $20 \mathrm{ml}$ of saline, followed by $100 \mathrm{ml}$ of neutral phosphate-buffered formalin (4\%; Thermo Fisher Scientific). Brains were removed, incubated in $20 \%$ sucrose at $4^{\circ} \mathrm{C}$ until they sank, and then sectioned at $40 \mu \mathrm{m}$ on a freezing microtome in three series. For all c-Fos and DsRed immunohistochemical staining that involved visualization using a diaminobenzidine reaction, the sections were incubated overnight with primary antiserum (c-Fos, 1:20,000; DsRed, 1:10,000) and then incubated in the respective secondary antibodies for $2 \mathrm{~h}$, followed by incubation in $\mathrm{ABC}$ reagents (1:1000; Vector Laboratories) for $90 \mathrm{~min}$, then washed again and incubated in a $0.06 \%$ solution of 3,3-diaminobenzidine tetrahydrochloride (Sigma-Aldrich) or $0.06 \%$ solution of 3,3-diaminobenzidine tetrahydrochloride and $0.05 \% \mathrm{CoCl}_{2}$ and $0.01 \% \mathrm{NiSO}_{4}(\mathrm{NH} 4)$ in PBS plus $0.02 \% \mathrm{H}_{2} \mathrm{O}_{2}$ for 5 $\mathrm{min}$. Finally, the sections were mounted on slides, dehydrated, cleared, and coverslipped. Sections for immunofluorescence staining were incubated in fluorescent-labeled secondary antibody $(\mathrm{Ab})$ for $2 \mathrm{~h}$ and coverslipped with DAPI-infused fluorescence mounting media.

Antibody characterization. The rabbit polyclonal Fos antibody was raised against a synthetic peptide including residues 4-17 from human c-Fos (rabbit polyclonal Ab; catalog \#Ab5, Oncogene Sciences; note that this $\mathrm{Ab}$ is no longer commercially available). This antibody stained a single band of $55 \mathrm{kDa}$ on Western blots from rat brain (technical information from manufacturer). c-Fos staining with the Ab5 antiserum is found in many CNS structures only when neurons within these structures have recently been physiologically stimulated.

The rabbit polyclonal antibody against mCherry was raised against DsRed (catalog \#632496, Clontech), and the specificity of immunostaining for DsRed was indicated by the lack of detectable immunostaining in uninjected mice.

For all secondary antibody immunohistochemical controls, the primary antibodies were omitted and the tissue showed no immunoreactivity above background. Secondary antibodies included the following: donkey anti-rabbit Alexa Fluor 546 (1:500; Invitrogen) and donkey antirabbit biotinylated (1:500; Invitrogen).

Packaging of DIO-hM3Dq and DIO-hM4D AAVs. We used the pAAV-hSyn-DIO-hM3D-mCherry and pAAV-hSyn-DIO-hM4D-mCherry plasmids (gift from B. Roth, UNC Chapel Hill, North Carolina) to provide the Cre-dependent hM3D transgene for packaging into AAV2/10. Packaging was performed using a standard triple-transfection protocol to generate helper virus-free pseudotyped AAV2/10 virus (Anaclet et al., 2015). An AAV 2/10 rep/cap plasmid provided AAV2 replicase and AAV10 capsid functions (Gao et al., 2002; De et al., 2006), while adenoviral helper functions were supplied by the pHelper plasmid (Stratagene). Briefly, AAV-293 cells were transfected via calcium phosphate precipitation with 1.33 pmol pHelper, and 1.15 pmol each of AAV2/10 and an AAV vector plasmid (double floxed). The cells were harvested $72 \mathrm{~h}$ later, and the pellets were resuspended in DMEM, freeze-thawed three times and centrifuged to produce a clarified viral lysate. The vector stocks were titered by real-time PCR using an Eppendorf Realplex machine as previously described (Gao et al., 2002). The titer of the preparations ranged from $\sim 1 \times 1012$ to $1 \times 1013$ vector genomes copies $/ \mathrm{ml}$. Before initiating the in vivo experiments, an absolute requirement for Cre-enabled expression of hM3Dq and hM4Di was confirmed in vitro using 293 cre cells.

Packaging of DTA-AAV. Drs. P. Fuller (BIDMC), O. Malyshevskaya and M. Lazarus (Tsukuba University) developed a new and enhanced version of our previously published DTA (Kaur et al., 2013), which was used in the current study. For the pAAV-FLEX-DTA plasmid, a FLEXDTA cassette that consists of ( $5^{\prime}$ to $\left.3^{\prime}\right)$ a lox 2272 site, an mCherry coding sequence, a human growth hormone polyadenylation signal sequence, a loxP site, an inverted DTA sequence, and inverted lox 2272 and loxP sites was synthesized by Eurofins Genomics K.K. and inserted between the $\mathrm{ClaI}$ and BamH I restriction sites in a pAAV-MCS vector (Stratagene). In this design, mCherry was expressed in all non-cre-recombinase cells within the injection field, thereby allowing us to ascertain (1) the anatomic extent of the injection and (2) "survival" of the non-crerecombinase cells intermingled with the cre-recombinase cells targeted 
A
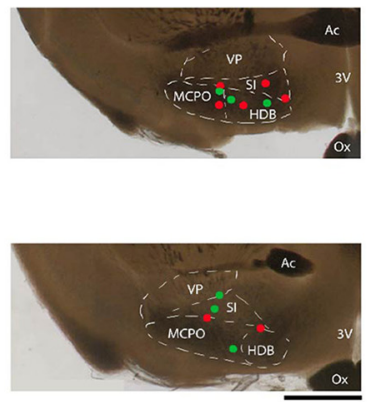

D

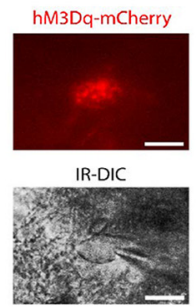

H

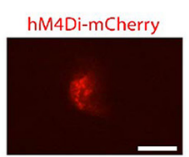

IR-DIC

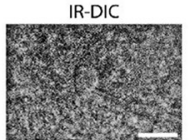

L

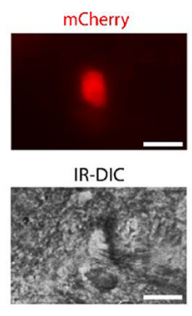

M
B

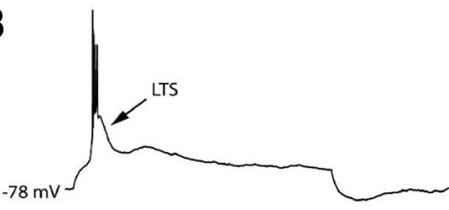

C

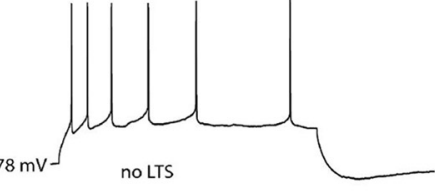

CNO
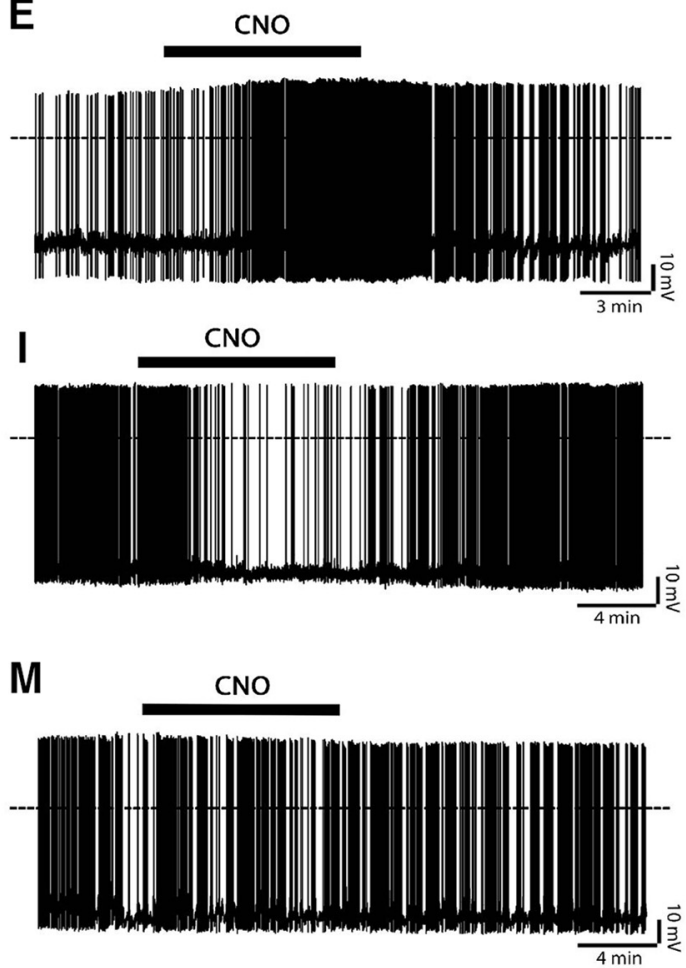
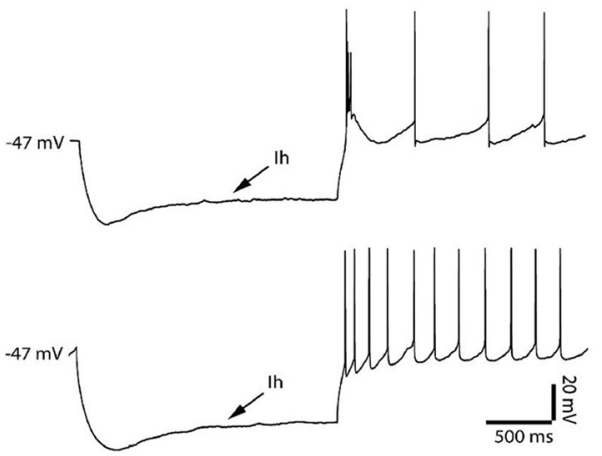

F
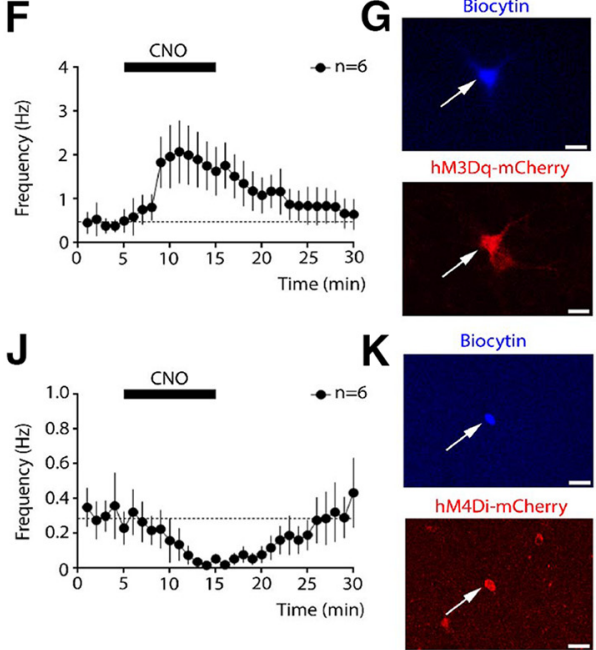

N
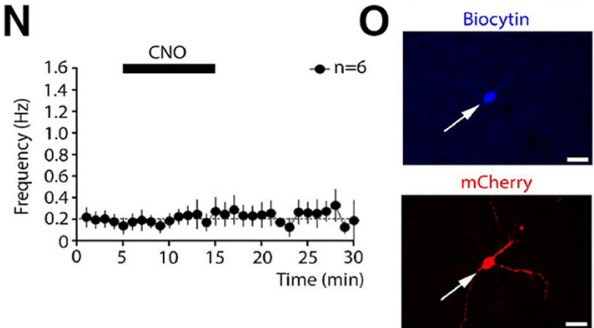

\section{P}

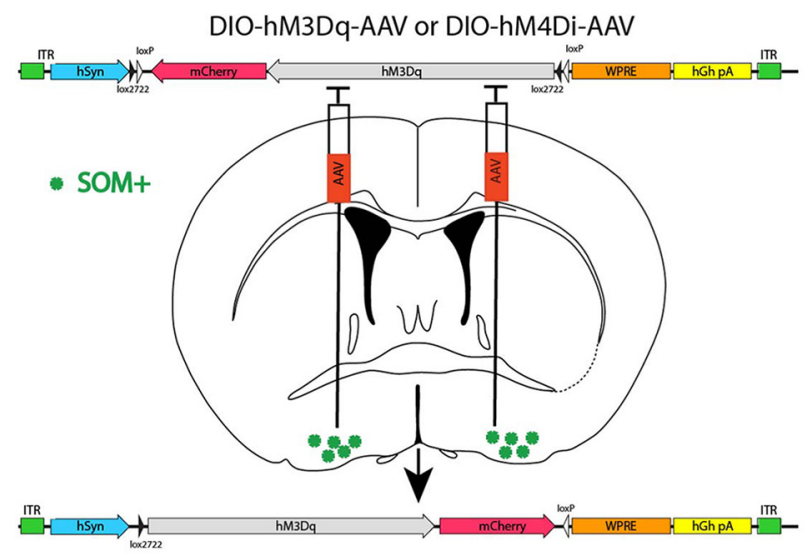

Q

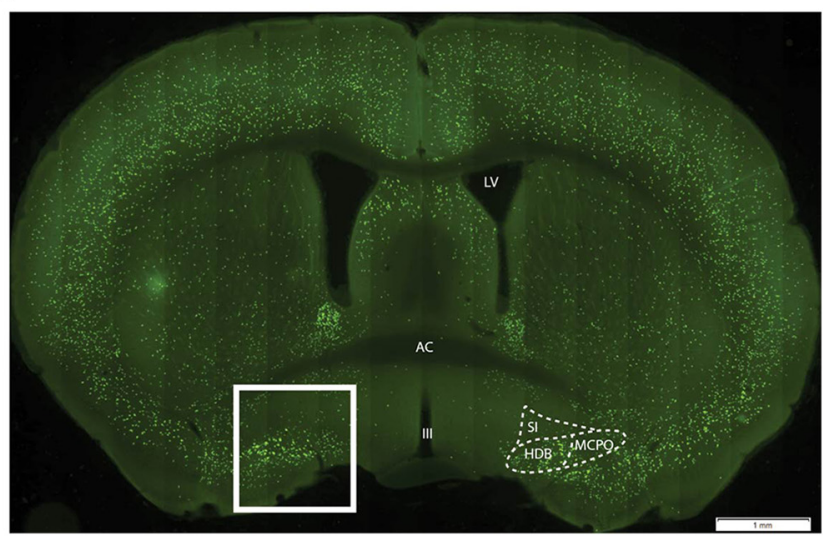

Figure 1. Evidence that $\mathrm{BF}^{\mathrm{SOM}} \mathrm{hM}_{3 \mathrm{Dq}}{ }^{+}$and $\mathrm{hM} 4 \mathrm{Di}{ }^{+}$neurons are excited and inhibited, respectively, by $\mathrm{CNO}$ in in vitro brain slices, experimental design, and $\mathrm{BF}{ }^{\mathrm{SOM}}$ cell distribution. Injections of DI0-hM3Dq-mCherry-AAV, DI0-hM4Di-mCherry-AAV, or DI0-mCherry-AAV were placed into the BF of SOM-ires-Cre mice, resulting respectively in the expression of hM3Dq-mCherry, hM4Di$\mathrm{mCherry}$, or $\mathrm{mCherry}$ in $\mathrm{BF}^{\mathrm{SOM}}$ neurons. Whole-cell recordings in brain slices were conducted 5- 6 weeks after the AAV injections. $A$, Microphotographs showing the distribution of the recorded neurons labeled with biocytin. After incubation in fluorescent streptavidin, 13 of 29 recorded neurons were recovered, mapped, and represented (red dots, indicating BF ${ }^{\mathrm{SOM}}$ neurons with $\mathrm{LTS}, n=$ 7; green dots representing non-LTS BF ${ }^{S O M}$ neurons, $n=6$ ) over the images of two recorded slices (rostral level, top image; caudal level, lower image). Scale bar, $1 \mathrm{~mm}$. Ac, Anterior commissure; $3 \mathrm{~V}$, third ventricle; $0 \mathrm{X}$, optical chiasm; $\mathrm{VP}$, ventral pallidum; $\mathrm{Sl}$, substantia innominata; $\mathrm{MCPO}$, magnocellular preoptic nucleus; $\mathrm{HDB}$, horizontal diagonal band). $\boldsymbol{B}, \mathrm{C}$, Firing properties of two distinct types of $\mathrm{BF}^{\mathrm{SOM}}$ neurons: one group of $\mathrm{BF}^{\mathrm{SOM}}$ neurons responds to depolarizing (left) and hyperpolarizing (right) current pulse protocols with $\mathrm{LTS}(\boldsymbol{B})$, and the other group has no $\mathrm{LTS}(\boldsymbol{C})$. The vast majority of $\mathrm{BF}^{\mathrm{SOM}}$ neurons have an $I_{\mathrm{h}}$. D, E, hM3Dq-mCherry-expressing $\mathrm{BF}^{\mathrm{SOM}}$ neurons (top) visualized under IR-DIC during whole-cell recordings (bottom; (Figure legend continues.) 
by DTA. See Figure $5 B$ for construct (CMV- $\beta$-globin-DIO-mCherryDTA-hGH pA) details.

AAV of serotype rh10 for AAV-FLEX-DTA were generated by tripartite transfection (AAV-rep2/caprh10 expression plasmid, adenovirus helper plasmid, and pAAV plasmid) into 293A cells. After $3 \mathrm{~d}$, the 293A cells were resuspended in artificial CSF (ACSF), freeze thawed four times, and treated with Benzonase nuclease (Millipore) to degrade all forms of nonviral DNA and RNA. Subsequently, the cell debris were removed by centrifugation, and the virus titer in the supernatant was determined with an AAVpro Titration Kit for Real Time PCR (Takara).

Whole-cell in vitro experiments. Bilateral injections (120 nl) of DIOhM3Dq-mCherry-AAV, DIO-hM4Di-mCherry-AAV or DIO-mCherry$\mathrm{AAV}$ were placed into the $\mathrm{BF}$ of SOM-Cre mice $(n=11$ mice). Five to 6 weeks after AAV injections, the mice were used for in vitro electrophysiological recordings. Mice were deeply anesthetized with isoflurane (inhalation; $5 \%$ in oxygen) and transcardially perfused with ice-cold cutting ACSF [ $N$-methyl-D-glucamine (NMDG)-based solution] containing the following (in mM): $100 \mathrm{NMDG}, 2.5 \mathrm{KCl}, 1.24 \mathrm{NaH}_{2} \mathrm{PO}_{4}, 30 \mathrm{NaHCO}_{3}, 25$ glucose, 20 HEPES, 2 thiourea, $5 \mathrm{Na}$-L-ascorbate, 3 Na-pyruvate, 0.5 $\mathrm{CaCl}_{2}$, and $10 \mathrm{MgSO}_{4}, \mathrm{pH} 7.3$, with $\mathrm{HCl}$ when carbogenated with $95 \% \mathrm{O}_{2}$ and $5 \% \mathrm{CO}_{2}(310-320 \mathrm{mOsm})$. Coronal slices (250 $\mu \mathrm{m}$ thickness) were cut in ice-cold cutting ACSF using a vibrating microtome (VT1200S, Leica). Slices were first kept in cutting ACSF at $37^{\circ} \mathrm{C}$ for $5 \mathrm{~min}$ and then transferred in normal ACSF at $37^{\circ} \mathrm{C}$. Slices were then allowed to gradually return to room temperature for an hour. Normal ACSF contained the following (in $\mathrm{mm}$ ): $120 \mathrm{NaCl}, 2.5 \mathrm{KCl}, 1.3 \mathrm{MgCl}_{2}, 10$ glucose, $26 \mathrm{NaHCO}_{3}, 1.24 \mathrm{NaH}_{2} \mathrm{PO}_{4}, 4 \mathrm{CaCl}_{2}, 2$ thiourea, $1 \mathrm{Na-L}-$ ascorbate, and $3 \mathrm{Na}$-pyruvate, $\mathrm{pH} 7.4$ when carbogenated with $95 \% \mathrm{O}_{2}$ and $5 \% \mathrm{CO}_{2}(310-320 \mathrm{mOsm})$.

Slices containing the BF were recorded in oxygenated $\left(95 \% \mathrm{O}_{2}, 5 \%\right.$ $\mathrm{CO}_{2}$ ) normal ACSF at room temperature. Recordings were conducted in whole-cell configuration and in current-clamp mode using a K-gluconatebased pipette solution containing the following (in mM): $120 \mathrm{~K}$-Gluconate, $10 \mathrm{KCl}, 3 \mathrm{MgCl} 2,10 \mathrm{HEPES}, 2.5 \mathrm{~K}-\mathrm{ATP}$, and $0.5 \mathrm{Na}-\mathrm{GTP}, \mathrm{pH} 7.2 \mathrm{ad}-$ justed with $\mathrm{KOH}(280 \mathrm{mOsm})$. Biocytin $(0.5 \%)$ was added to the pipette solution to fill and mark the recorded neurons. Recordings were conducted using a MultiClamp 700B Amplifier, a Digidata 1440A Digitizer Interface, and pClamp version 10 software (Molecular Devices). Neurons showing changes in input resistance $>10 \%$ over time were excluded from the analysis. BF mCherry-labeled somatostatin neurons were visualized through a combination of fluorescence and infrared (IR)differential interference contrast (DIC) video microscopy using a fixedstage upright microscope (BX51WI, Olympus America) equipped with a Nomarski water-immersion lens $(40 \times / 0.8 \mathrm{NAW}$, Olympus $)$ and IRsensitive CCD camera (ORCA-ER, Hamamatsu). Images were acquired in real time using a Matlab (MathWorks) script.

Recording data were analyzed using Clampfit version 10 (Molecular Devices). Firing frequencies and membrane potentials were analyzed using MiniAnalysis (Synaptosoft) and Matlab (MathWorks). Data were represented as the mean \pm SEM; $n$ indicates number of cells per group.

\section{$\leftarrow$}

(Figure legend continued.) scale bars, $20 \mu \mathrm{m}$ ) showed an increase in firing frequency in response to the bath application of $\mathrm{CNO}(1 \mu \mathrm{m}$; dotted lines, $0 \mathrm{mV})$. $\boldsymbol{F}$, Averaged response on the firing frequency of hM3Dq-expressing $B F^{5 O M}$ neurons $(n=6)$ to 10 min application of CNO (0.5-1 $\mu \mathrm{M}) . \mathbf{G}$, Confocal images of a recorded $\mathrm{BF}^{\mathrm{SOM}}$ neuron (filled with biocytin and labeled in blue; top) that expresses hM3Dq-mCherry (native fluorescence; bottom; scale bars, $20 \mu \mathrm{m}$ ). $\boldsymbol{H}, \mathbf{I}$, hM4Di-mCherry expressing BF ${ }^{\text {SOM }}$ neurons (top) visualized under IR-DIC (bottom; scale bars, $20 \mu \mathrm{m})$ reduced their firing frequency in response to CNO (1 $\mu \mathrm{m}$; dotted lines, $0 \mathrm{mV})$. $\boldsymbol{J}$, Averaged response of hM4Di-expressing $\mathrm{BF}^{\mathrm{SOM}}$ neurons to $\mathrm{CNO}(0.5-1 \mu \mathrm{m} ; n=6)$. $K$, Confocal image of a recorded $\mathrm{BF}^{\mathrm{SOM}}$ neuron (top, biocytin labeled in blue; bottom, mCherry native fluorescence; scale bars, $20 \mu \mathrm{m}) . \boldsymbol{L}-\boldsymbol{N}$, Non-hM3Dq or non-hM4Di expressing BF ${ }^{\mathrm{SOM}}$ neurons, recorded from SOM-Cre mice injected with DI0-mCherry-AAV, control injections (top: mCherry; bottom: IR-DIC; scale bars: $20 \mu \mathrm{m}$ ) did not respond to CNO ( $1 \mu \mathrm{m}$; dotted lines, $0 \mathrm{mV} ; n=6) . \mathbf{0}$, Confocal images of a recorded $\mathrm{BF}^{\mathrm{SOM}}$ neuron (top, biocytin labeled in blue; bottom, mCherry native fluorescence; scale bars, $20 \mu \mathrm{m}) . \boldsymbol{P}$, Experimental design for the chemogenetic-based in vivo experiments. $\mathbf{Q}$, Coronal section from a Som-ires-cre, lox-GFPL10 reporter cross (box shows targeted region of $\mathrm{BF}$; scale bar, $1 \mathrm{~mm}$ ).
Group means were compared using paired $t$ tests. The effects of CNO on firing frequency and membrane potential were analyzed by comparing 5 min of recordings just before CNO applications (control period) and during the last $5 \mathrm{~min}$ of a $10 \mathrm{~min} \mathrm{CNO}$ application. Figures were generated using Photoshop (Adobe), Igor Pro version 6 (WaveMetrics) and Prism 7 (GraphPad).

Immediately following the in vitro recordings, recorded slices were fixed in 10\% buffered formalin (overnight), then washed and incubated in streptavidin-conjugated Alexa Fluor 405 (1:500, 24 h; Invitrogen). Images were acquired using a confocal microscope (LSM 5 Pascal, Zeiss) and a slide scanner (VS120, Olympus).

\section{Results}

\section{In vitro $\mathrm{BF}^{\mathrm{SOM}}$ activation and inhibition}

Whole-cell current-clamp recordings in the BF revealed two populations of somatostatin-expressing $\left(\mathrm{BF}^{\mathrm{SOM}}\right)$ neurons with distinct firing properties (Fig. $1 A-C$ ). One population had large low-threshold spikes (LTSs) that supported burst firing when neurons were depolarized from hyperpolarized potentials (17 of 29 recorded neurons; Fig. $1 B$ ), while the second population showed tonic firing and no LTSs (12 of 29 recorded neurons; Fig. $1 C)$. The hyperpolarization-activated cation current $\left(I_{\mathrm{h}}\right)$ was present in the majority of $\mathrm{BF}^{\mathrm{SOM}}$ neurons (25 of 29 neurons). Both subtypes of $\mathrm{BF}^{\mathrm{SOM}}$ neurons were capable of expressing hM3Dq (BF $\left.{ }^{\text {SOM-hM3Dq-mCherry }}\right)$ or hM4Di (BF $\left.{ }^{\text {SOM-hM4Di-mCherry }}\right)$ receptors following injections of DIO-hM3Dq-mCherry-AAV and DIO-hM4Di-mCherry-AAV in SOM-ires-Cre mice and responded to bath application of CNO $(0.5-1 \mu \mathrm{M})$. We tested the response to $\mathrm{CNO}$ in $18 \mathrm{BF}^{\mathrm{SOM}}$ neurons. $\mathrm{CNO}$ increased the firing frequency of $\mathrm{BF}^{\text {SOM-hM3Dq-mCherry }}$ neurons (control, $0.47 \pm 0.25$ $\mathrm{Hz}$; $\mathrm{CNO}, 1.81 \pm 0.66 \mathrm{~Hz} ; n=6 ; p=0.0284$, paired $t$ test; Fig. $1 D-G)$, and this effect was accompanied by a membrane depolarization (control, $-44.31 \pm 2.02 \mathrm{mV}$; CNO, $-39.26 \pm 1.10$ $\mathrm{mV} ; n=6 ; p=0.0018$, paired $t$ test). Both firing frequency and membrane potential returned to control levels after $15 \mathrm{~min}$ of $\mathrm{CNO}$ washout. $\mathrm{CNO}$ decreased the firing frequency of $\mathrm{BF}^{\text {SOM-hM4Di-mCherry }}$ neurons (control: $0.31 \pm 0.12 \mathrm{~Hz}$; CNO: $0.04 \pm 0.02 \mathrm{~Hz} ; n=6 ; p=0.0199$, paired $t$ test; Fig. $1 H-K)$ and hyperpolarized their membrane potential (control, $-45.52 \pm$ $1.00 \mathrm{mV} ; \mathrm{CNO},-49.61 \pm 0.90 \mathrm{mV} ; n=6 ; p=0.0001$, paired $t$ test). Both effects were reversed after $15 \mathrm{~min}$ washout. CNO had no effect on $\mathrm{BF}^{\text {SOM-mCherry }}$ neurons that lacked $\mathrm{hM} 3 \mathrm{Dq}$ or hM4Di receptors and only expressed mCherry following injections of DIO-mCherry-AAV (control injections; Fig. $1 L-O$ ). No changes of firing frequency (control, $0.19 \pm 0.08 \mathrm{~Hz} ; \mathrm{CNO}$, $0.21 \pm 0.10 \mathrm{~Hz} ; n=6 ; p=0.1873$, paired $t$ test) or in membrane potential (control, $-40.94 \pm 1.97 \mathrm{mV} ; \mathrm{CNO},-40.90 \pm 2.14 \mathrm{mV}$; $n=6 ; p=0.4645$, paired $t$ test $)$ in response to $\mathrm{CNO}(1 \mu \mathrm{M})$ were observed in $\mathrm{BF}^{\text {SOM-mCherry }}$ neurons, confirming that $\mathrm{CNO}$ mediated activation or inhibition of $\mathrm{BF}^{\mathrm{SOM}}$ neurons occurs only in neurons expressing hM3Dq and hM4Di receptors.

\section{In vivo $\mathrm{BF}^{\text {SOM }}$ chemogenetic activation}

Following bilateral injections of hM3Dq-AAV, transduced somata $\left(\mathrm{hM}_{3} \mathrm{Dq}^{+}\right)$were consistently observed in the horizontal limb of the diagonal band, magnocellular preoptic area, and substantia innominata and spanned, rostrally caudally, from bregma +0.26 to -0.82 (Figs. $1 P, Q, 2 A$ ). As we have shown previously (Anaclet et al., 2014), the administration of CNO (the hM3Dq ligand; $0.3 \mathrm{mg} / \mathrm{kg}$, i.p.) consistently produced robust c-Fos expression in $\mathrm{hM}_{3} \mathrm{Dq}^{+}$neurons (Fig. $2 B$ ). To test the putative sleeppromoting action of $\mathrm{BF}^{\mathrm{SOM}}$ neurons in vivo, $\mathrm{BF}^{\mathrm{SOM}-\mathrm{hM} 3 \mathrm{Dq}}$ mice $(n=8)$ received injection of $\mathrm{CNO}(0.3$ or $0.9 \mathrm{mg} / \mathrm{kg})$ at the beginning of the dark period, a time of high waking drive in mouse 
A

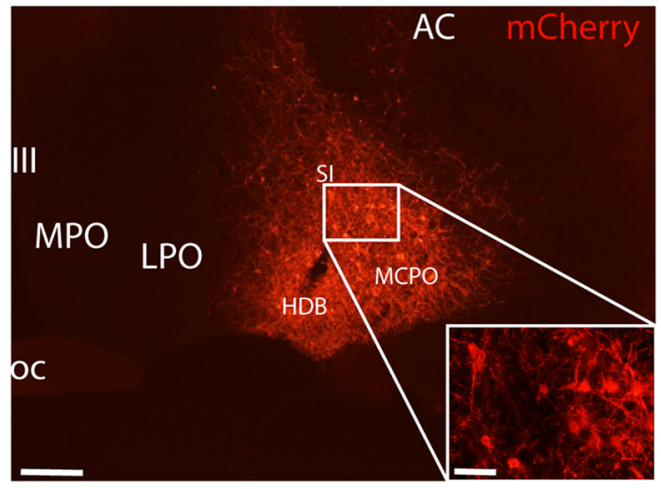

B

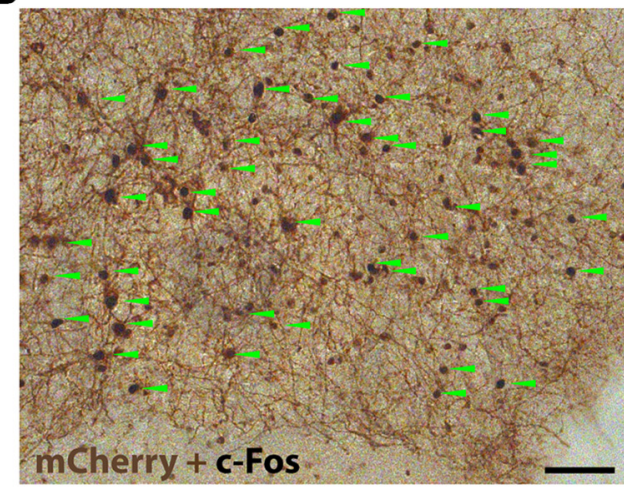

Wakefulness
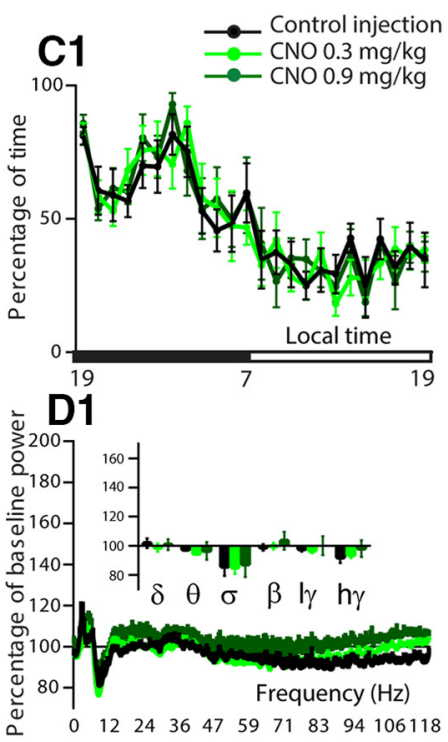

E1

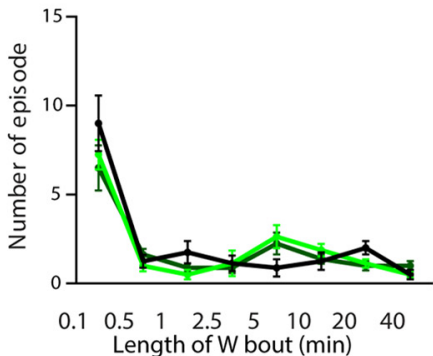

F1

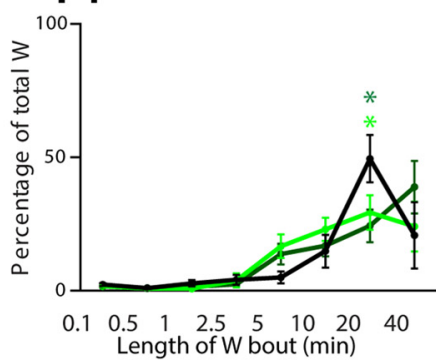

NREM Sleep

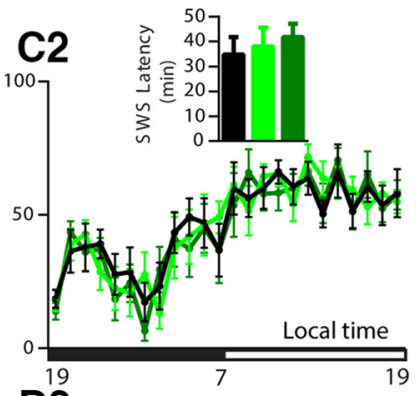

D2

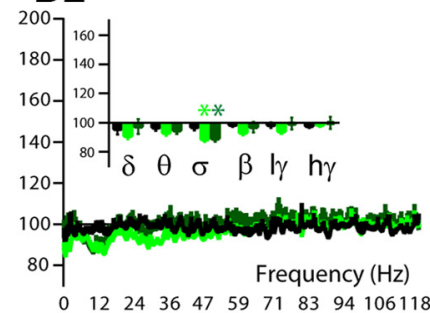

E2

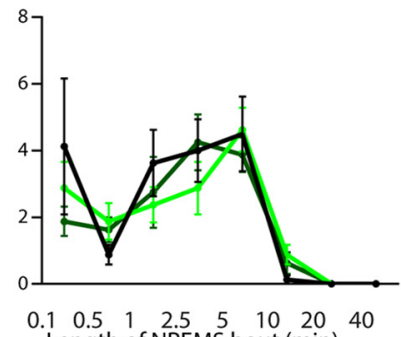

F2

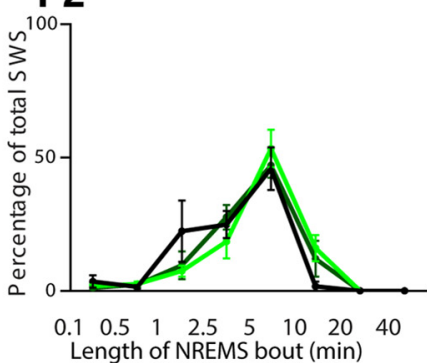

REM Sleep

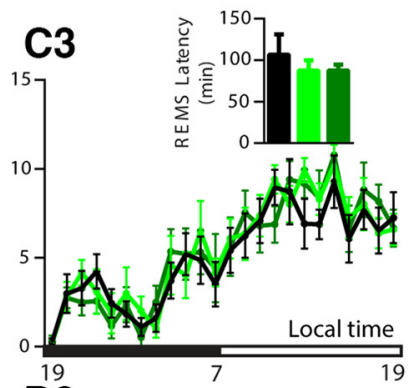

D3

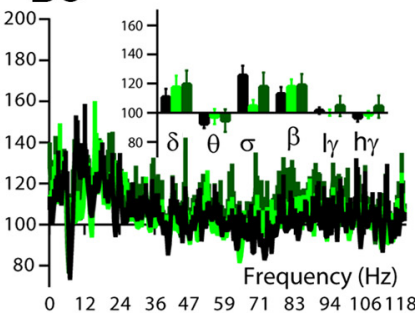

E3

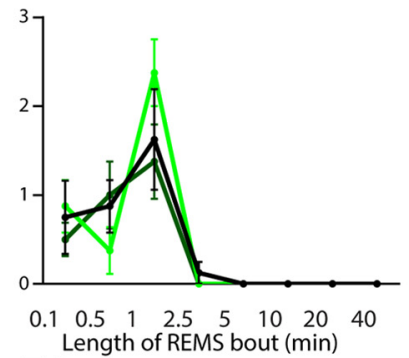

F3

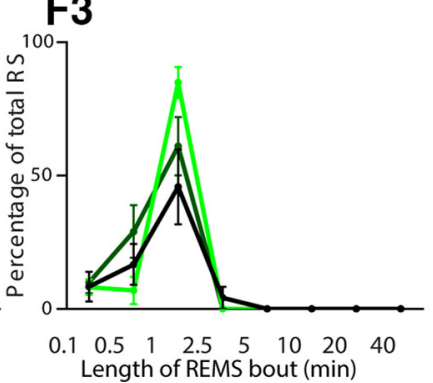

Figure 2. Absence of sleep-wake changes following chemogenetic activation of $\mathrm{BF}^{\mathrm{SOM}}$ neurons. $\boldsymbol{A}, \boldsymbol{B}$, Photomicrographs showing transfection of $\mathrm{BF}^{\mathrm{SOM}}$ neurons $(\boldsymbol{A})$ and their robust activation (B) following CNO in vivo (green arrows indicate hM3Dq + cells expressing c-Fos). C1-F3, Sleep-wake phenotypes following injection of vehicle and CNO (0.3 mg/kg and $0.9 \mathrm{mg} / \mathrm{kg})$ in BF ${ }^{\text {SOM-hM3Dq }}$ mice. C, Hourly amount ( \pm SEM) of the vigilance stages and sleep latencies in $B F^{\text {SOM-hMBDa }}$ mouse group $(n=8$ mice). $\boldsymbol{D}$, Power spectrum changes ( \pm SEM) over baseline during the $3 \mathrm{~h}$ postinjection period for vehicle injection compared with the $3 \mathrm{~h}$ postinjection period for $\mathrm{CNO}(0.3$ and $0.9 \mathrm{mg} / \mathrm{kg})$ administration and the quantitative changes ( \pm SEM) in power for the delta $(\delta .0 .5-5 \mathrm{~Hz})$, theta $(\theta, 5-9 \mathrm{~Hz})$, sigma $(\sigma, 9-15 \mathrm{~Hz})$, beta $(\beta, 15-30 \mathrm{~Hz})$, low-gamma $(l \gamma, 30-60 \mathrm{~Hz})$, and high-gamma (h $\gamma, 60-120 \mathrm{~Hz})$ frequency bands $(n=8 \mathrm{mice}) . \boldsymbol{E}, \boldsymbol{F}$, Number of episodes $( \pm S E M)$ of wakefulness (W), NREM sleep, or REM sleep in each bout length $(\boldsymbol{E})$ and time-weighted frequency histograms $(\boldsymbol{F})$ showing the proportion ( \pm SEM) of wakefulness, (Figure legend continues.) 
(Fig. 2C). CNO dosage had no effect on NREM sleep (one-way ANOVA, $F_{(1.89,13.22)}=0.32, p=0.72$ ) or REM sleep (one-way ANOVA, $F_{(1.26,8.84)}=0.45, p=0.56$ ) latency, suggesting that the activation of $\mathrm{BF}{ }^{\mathrm{SOM}}$ neurons does not affect sleep onset. CNO dosage had no effect on the hourly amount of NREM sleep (twoway ANOVA, $F_{(2,14)}=0.83, p=0.45$ ) or REM sleep (two-way ANOVA, $\left.F_{(2,14)}=1.43, p=0.27\right)$ amount, suggesting that the activation of $\mathrm{BF}^{\mathrm{SOM}}$ neurons does not affect sleep behavior. Cortical EEG power spectral analysis during the $3 \mathrm{~h}$ postinjection confirmed that the CNO dosage did not affect frequency distribution during the three vigilance stages (Fig. $2 D$ ), indicating no major influence of $\mathrm{BF}^{\mathrm{SOM}}$ neurons on cortical activity. Power was, however, reduced during NREM sleep following CNO administration (low CNO dose, $88.5 \pm 1.8 \%$; high CNO dose, $89.2 \pm 2.2 \%$ vs $97.0 \pm 2.3 \%$ of baseline sigma power during NREM sleep; $p=0.0008$ and 0.002 , respectively, Bonferroni's multiple-comparisons test), suggesting a possible decrease in spindle activity during NREM sleep. Sleep architecture during the $3 \mathrm{~h}$ postinjection bout number and duration was not affected by CNO dosage (Fig $2 E, F)$, and CNO administration $(0.3 \mathrm{mg} / \mathrm{kg}$, i.p.) during the light period did not affect NREM sleep $\left(F_{(23,161)}=\right.$ $1.36, p=0.14)$ or REM sleep $\left(F_{(23,161)}=1.10, p=0.35\right)$ hourly distribution, indicating a very modest influence of $\mathrm{BF}^{\mathrm{SOM}}$ neurons on sleep-wake regulation. Our findings therefore fail to confirm a wake- or sleep-promoting role for $\mathrm{BF}^{\mathrm{SOM}}$ neurons in vivo and, moreover, are inconsistent with those from a prior optogenetic study suggesting that $\mathrm{BF}^{\mathrm{SOM}}$ neurons are acutely sleep promoting in vivo (Xu et al., 2015).

\section{In vivo $\mathrm{BF}^{\mathrm{SOM}}$ chemogenetic inhibition}

Similar to the activation experiments, acute inhibition of $\mathrm{BF}^{\mathrm{SOM}}$ neurons had limited effects on sleep-wake quantity or quality in $\mathrm{BF}^{\text {SOM-hM4Di }}$ mice $(n=5$; Fig. 3$)$. Specifically, the administration of CNO ( 0.3 or $0.9 \mathrm{mg} / \mathrm{kg}$, i.p.) was without effect on NREM sleep (one-way ANOVA, $F_{(1.32,5.28)}=0.27, p=0.69$ ) or REM sleep (one-way ANOVA, $F_{(1.06,4.23)}=0.39, p=0.58$ ) latency (Fig. $3 A 2-A 3)$, suggesting that inhibition of $\mathrm{BF}^{\mathrm{SOM}}$ neurons does not affect sleep onset. $\mathrm{CNO}$ dosage was also without effect on the hourly amount of wakefulness (two-way ANOVA, $F_{(2,8)}=3.76$, $p=0.07$ ), suggesting that inhibition of $\mathrm{BF}^{\mathrm{SOM}}$ neurons did not affect waking behavior (Fig. 3A1). Cortical EEG power spectral analysis during the $3 \mathrm{~h}$ postinjection period confirmed that $\mathrm{CNO}$ dosage did not affect frequency bands during wakefulness (twoway ANOVA, $F_{(10,30)}=1.60, p=0.15$; Fig. 3B1), indicating that $\mathrm{BF}^{\mathrm{SOM}}$ neurons are not necessary for cortical activation. The higher dose of $\mathrm{CNO}(0.9 \mathrm{mg} / \mathrm{kg})$ did, however, decrease sigma, beta, and low gamma power band compared with both control and low $\mathrm{CNO}$ $(0.3 \mathrm{mg} / \mathrm{kg})$ injections during NREM sleep (Fig. 3B2), indicative of a decrease of spindle and fast activity during NREM sleep. Sleep architecture during the $3 \mathrm{~h}$ postinjection, bout number, and duration, was not affected by $\mathrm{CNO}$ dosage (Fig. $3 C, D$ ) confirming no major influence of $\mathrm{BF}^{\mathrm{SOM}}$ neurons on sleep-wake phenotype. These results suggest that $\mathrm{BF}^{\mathrm{SOM}}$ neurons are not necessary for sleep onset and maintenance, although the spectral results sug-

\footnotetext{
$\leftarrow$

(Figure legend continued.) NREM sleep, or REM sleep amounts in each bout length to the total amount of wakefulness, NREM sleep, or REM sleep during the $3 \mathrm{~h}$ postinjection period for vehicle injection compared with the $3 \mathrm{~h}$ postinjection period for $\mathrm{CNO}(0.3$ and $0.9 \mathrm{mg} / \mathrm{kg})$ administration $(n=8)$. Light green star $p<0.05$ between CNO $0.3 \mathrm{mg} / \mathrm{kg}$ and control injection; dark green star $p<0.05$ between $C N 00.9 \mathrm{mg} / \mathrm{kg}$ and control injection, two-way ANOVA followed by a post hoc Bonferroni test. Scale bars: $\boldsymbol{A}, 400 \mu \mathrm{m} ; \boldsymbol{A}$ inset, $100 \mu \mathrm{m} ; \boldsymbol{B}, 70 \mu \mathrm{m}$.
}

gest that $\mathrm{BF}^{\mathrm{SOM}}$ neurons may facilitate the "dampening down" of cortical activity during sleep.

\section{In vivo $\mathrm{BF}^{\mathrm{SOM}}$ optogenetic activation}

As chemogenetic activation of $\mathrm{BF}^{\mathrm{SOM}}$ neurons was ineffective at inducing changes in wakefulness or sleep, we next sought to determine whether activation of this population using an optogenetic strategy could induce a behavioral state transition. $\mathrm{BF}^{\mathrm{SOM}-\mathrm{ChR} 2}$ mice ( $n=7$; Fig. 4A-B2) received blue light pulses delivered through the optical fiber at frequencies close to the native firing frequency of these neurons in vivo (based upon the study by Xu et al., 2015; $10 \mathrm{~ms}$ pulses delivered at $2.5 \mathrm{~Hz}$ for $1 \mathrm{~min}$; Figure 4C1) and at a previously investigated stimulus frequency (of $10 \mathrm{~ms}$ pulses delivered at $10 \mathrm{~Hz}$ for $1 \mathrm{~min}$; Figure 4C2; Xu et al., 2015) once every $10 \mathrm{~min}$ for $3 \mathrm{~h}$ during the light period (between 9:00 A.M. and 3:00 P.M.). Consistent with our chemogenetic findings, optogenetic activation of $\mathrm{BF}^{\mathrm{SOM}}$ neurons did not increase the probability of a transition to NREM (or REM) sleep at either stimulation frequency tested. As a positive control for this stimulation, we similarly bilaterally stimulated $\mathrm{BF}^{\mathrm{VGAT}-\mathrm{ChR} 2}$ neurons $(n=2$ mice; Fig. 4D), which induced a robust increase in wakefulness at both 2.5 and $10 \mathrm{~Hz}$. We therefore conclude that the activation of SOMcontaining neurons within the BF (confirmed using two complementary yet distinct approaches) does not acutely drive sleep or wakefulness in mice.

\section{$\mathrm{BF}^{\text {SOM }}$ genetically targeted chronic ablation}

To test the sleep-wake effect of the chronic loss of $\mathrm{BF}^{\mathrm{SOM}}$ neurons, we placed bilateral injections of AAV-DTA into the BF of SOM-ires-cre,lox-L10GFP mice (BF ${ }^{\text {SOM-DTA }}, n=11$ ) to selectively and chronically ablate $\mathrm{BF}^{\mathrm{SOM}}$ neurons (Fig. $5 \mathrm{~A}, \mathrm{~B}$ ). Histological analysis of the tissue revealed a $>90 \%$ bilateral reduction in $\mathrm{BF}^{\mathrm{SOM}}$ cells $\left(\mathrm{GFP}^{+}\right)$across the anatomic BF (Fig. $\left.5 C-F\right)$. With respect to the physiology of these mice, the chronic loss of $\mathrm{BF}^{\mathrm{SOM}}$ neurons $\left(\mathrm{BF}^{\text {SOM-DTA }}\right)$ resulted in cycles of sleep and wakefulness that were comparable to control mice $\left(\mathrm{BF}^{\mathrm{SOM} \text {-mCherry }}, n=5\right.$; same genotype as $\mathrm{BF}^{\text {SOM-DTA }}$ mice; bilateral injection of AAVmCherry for viral vector injection control) in the baseline condition, with minor exceptions. The $24 \mathrm{~h}$ wakefulness distribution was not affected by the loss of $\mathrm{BF}^{\mathrm{SOM}}$ neurons (two-way ANOVA, $F_{(1,14)}=1.16, p=0.69$; Figure 5G1), and, similar to control mice, $\mathrm{BF}^{\mathrm{SOM}-\mathrm{DTA}}$ mice were more awake during the dark period compared with the light period (light-dark interaction: two-way ANOVA, $F_{(1,14)}=153.3, p<0.0001$; Fig. 5H1). NREM sleep and REM sleep displayed opposite variations (Fig. 5G2,G3,H2,H3). However, wakefulness was significantly increased during the first $4 \mathrm{~h}$ of the dark period, a time of high waking drive in the mouse $(87.3 \pm 2.6 \%$ vs $73.1 \pm 5.2 \%$ of wakefulness in control mice; $p=$ 0.015 , unpaired $t$ test, $t=2.76, \mathrm{df}=14$; Figure $5 \mathrm{H} 1$ ). The wakefulness amount increases during the first $4 \mathrm{~h}$ of the dark period were at the expense of both NREM sleep (Fig. 5H2) and REM sleep (Fig. 5H3). The increased wakefulness during the early active period in $\mathrm{BF}^{\text {SOM-DTA }}$ mice resulted from a significant decrease of the short wakefulness epoch $(<30$ s: $3.3 \pm 0.9$ vs $7.8 \pm$ 1.5 episodes in control mice; $p<0.0001$, Bonferroni's adjustment for multiple comparisons; Fig. 6A1) and a significant increase of the percentage of wakefulness from long wakefulness epochs ( $>40$ min: $88.0 \pm 3.2 \%$ vs $45.3 \pm 14.7 \%$ of wakefulness in control mice; $p<0.0001$, Bonferroni's adjustment for multiple comparisons; Fig. 6B1). At the same time, the number of mediumlength NREM sleep episodes $(1 \mathrm{~min}<$ NREM sleep epoch $<10$ min; Fig. 6A2) was significantly decreased in $\mathrm{BF}^{\text {SOM-DTA }}$ mice. The REM sleep epoch number was also affected (two-way 
Wakefulness
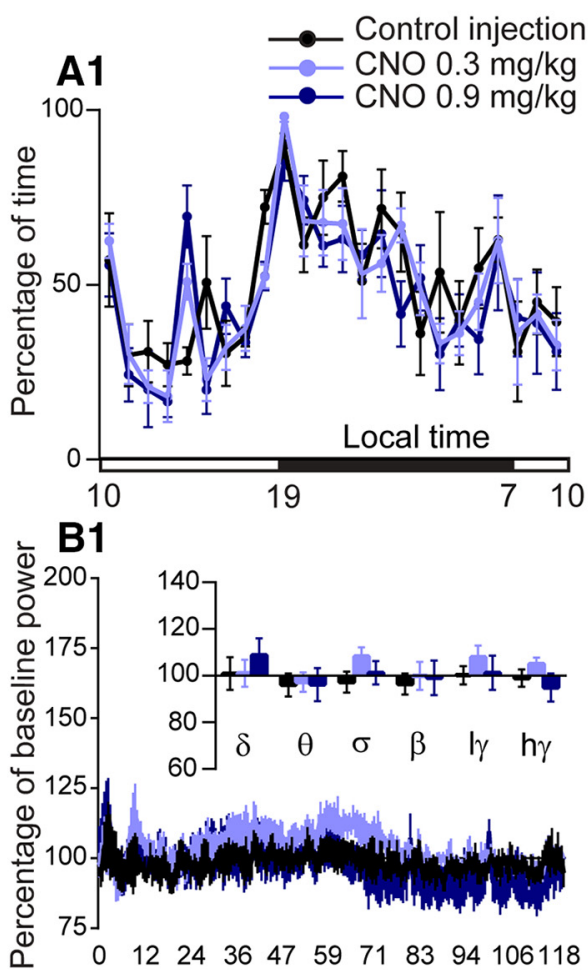

Frequency $(\mathrm{Hz})$
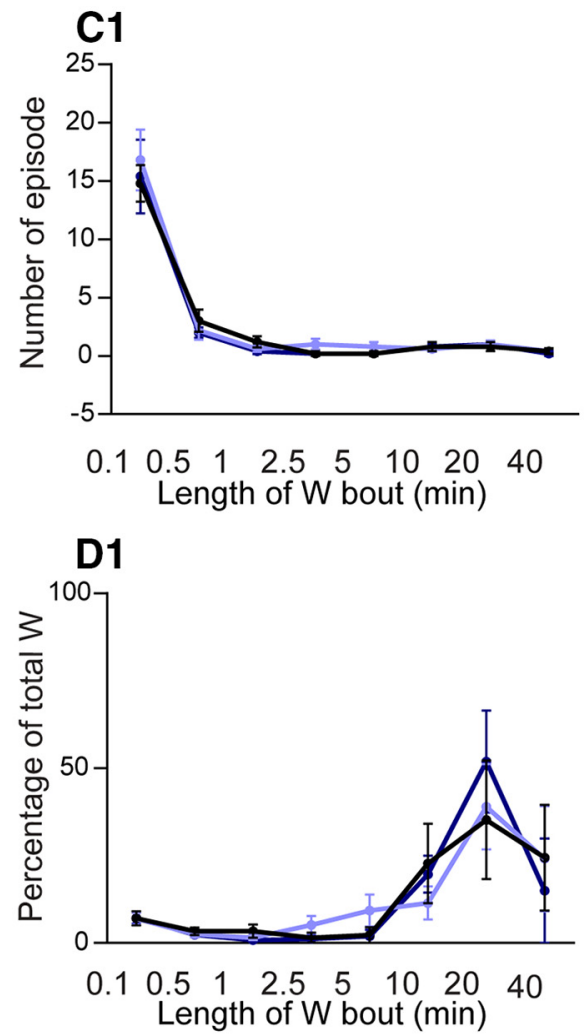

NREM Sleep

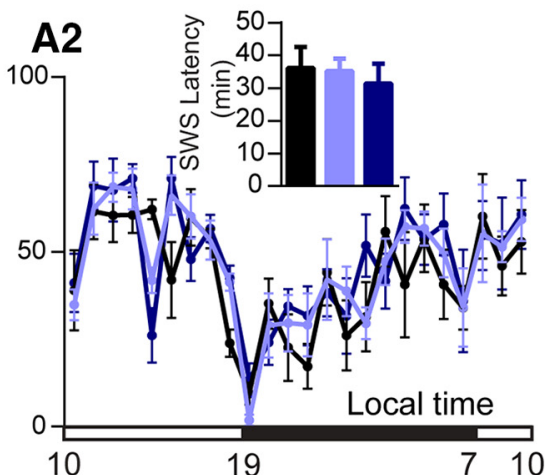

B2

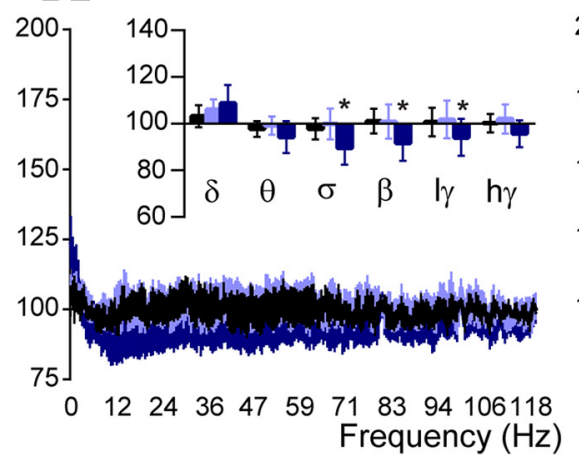

C2

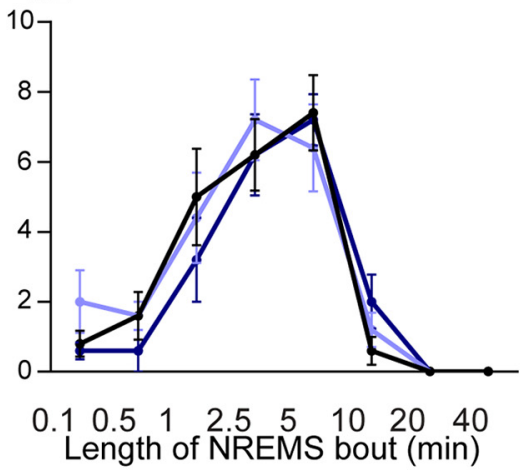

D2

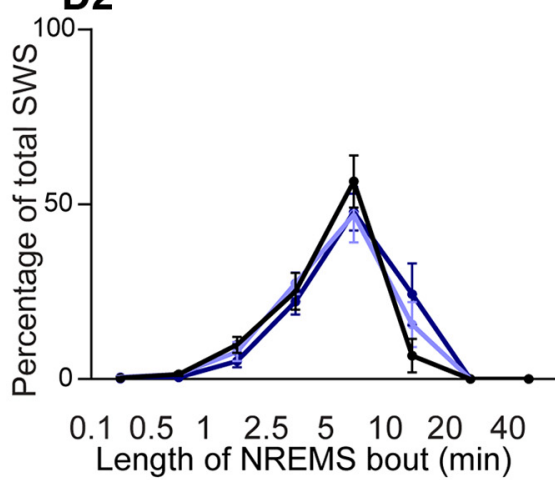

REM Sleep

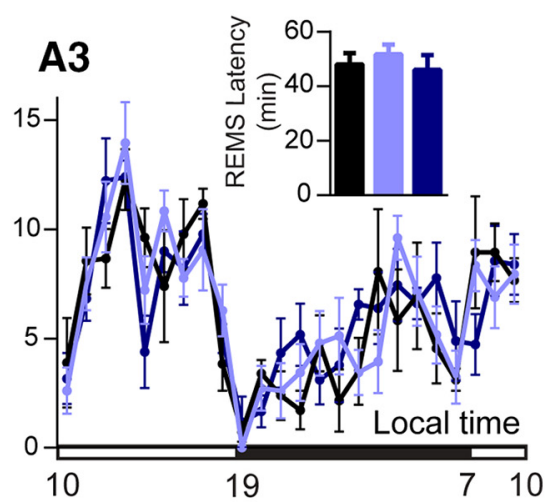

B3

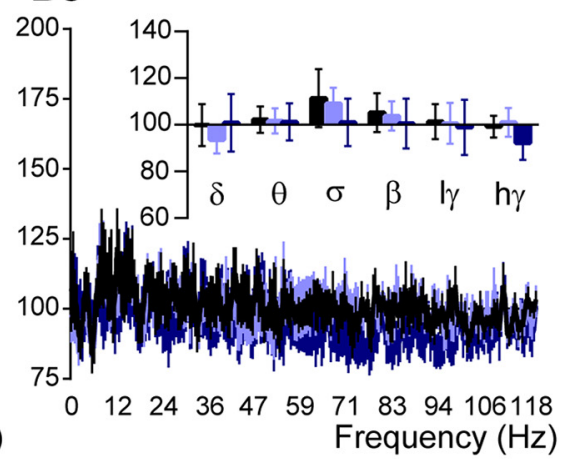

C3

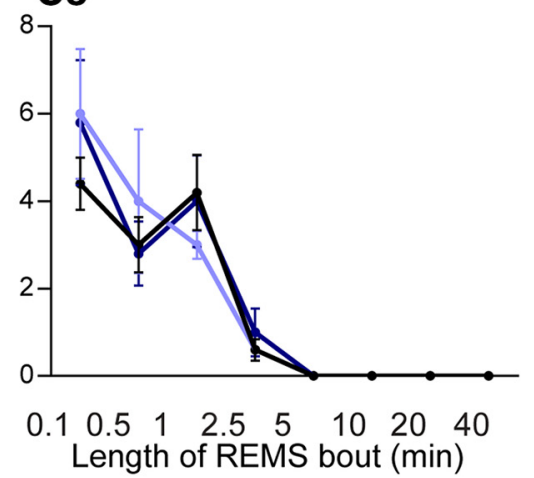

D3

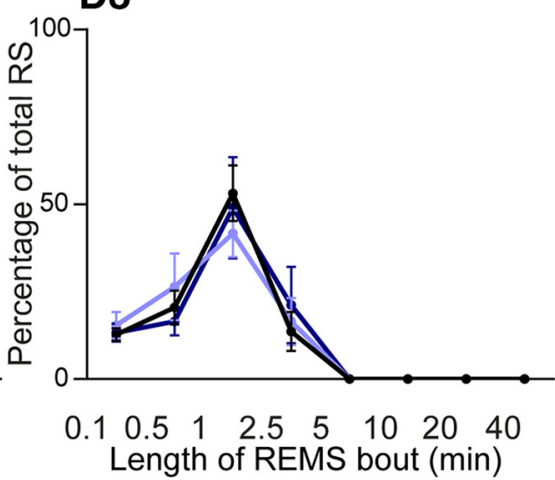

Figure 3. Absence of sleep-wake changes following chemogenetic inhibition of BF ${ }^{\text {SOM }}$ neurons. Sleep-wake phenotypes following the injection of vehicle and CNO (0.3 and 0.9 mg/kg) in $\mathrm{BF}^{\text {SOM-hM4Di }}$ mice. $A$, Hourly amount of wakefulness (W; A1), NREM sleep (NREMS; A2) and REM sleep (REMS; A3) and sleep latencies in BF ${ }^{\text {SOM-hM4Di }}$ mouse group ( $n=5$ mice). $B$, Power spectrum changes ( \pm SEM) over baseline during the $3 \mathrm{~h}$ postinjection period for vehicle injection compared with the $3 \mathrm{~h}$ postinjection period for $\mathrm{CNO}$ ( $0.3 \mathrm{and} 0.9 \mathrm{mg} / \mathrm{kg}$ ) administration and the quantitative changes ( \pm SEM) in power for the delta $(\delta, 0.5-5 \mathrm{~Hz})$, theta $(\theta, 5-9 \mathrm{~Hz})$, sigma $(\sigma, 9-15 \mathrm{~Hz})$, beta $(\beta, 15-30 \mathrm{~Hz})$, low-gamma $(\mathrm{l} \gamma, 30-60 \mathrm{~Hz})$, and high-gamma ( $\mathrm{h} \gamma, 60-120 \mathrm{~Hz})$ frequency bands ( $n=4$ mice). (1-C3, D1-D3, Number of episodes ( \pm SEM) of W, NREMS, or REMS in each bout length $(\boldsymbol{C})$ and in time-weighted frequency histograms (D) showing the proportion ( \pm SEM) of W, NREMS, or REMS amounts in each bout length to the total amount of wakefulness, NREM sleep, or REM sleep during the $3 \mathrm{~h}$ postinjection period for vehicle injection compared with the $3 \mathrm{~h}$ postinjection period for CNO ( 0.3 and $0.9 \mathrm{mg} / \mathrm{kg}$ ) administration $(n=5)$. * $p<0.05$ between CN0 $0.9 \mathrm{mg} / \mathrm{kg}$ and control injection, two-way ANOVA followed by a post hoc Bonferroni test. 


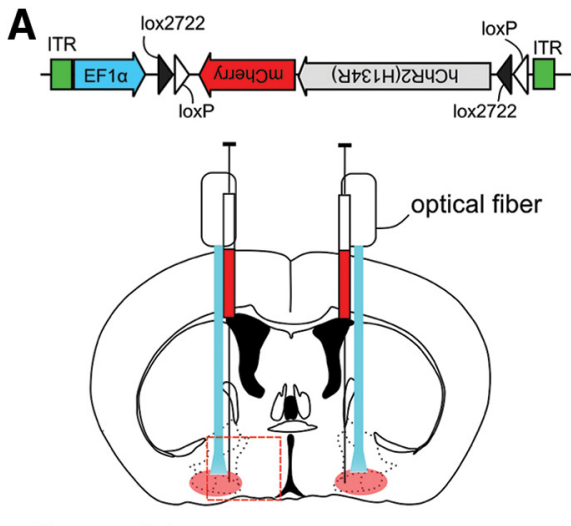

Bregma $-0.1 \mathrm{~mm}$

\section{B1}

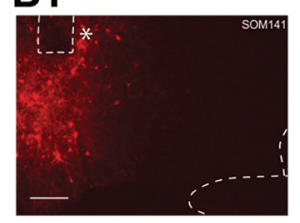

B2

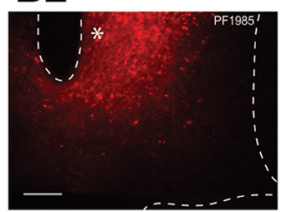

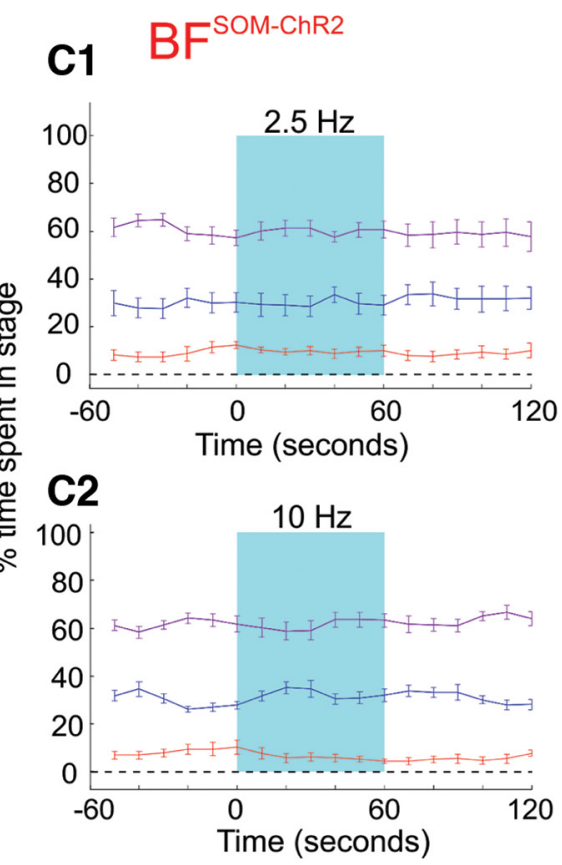
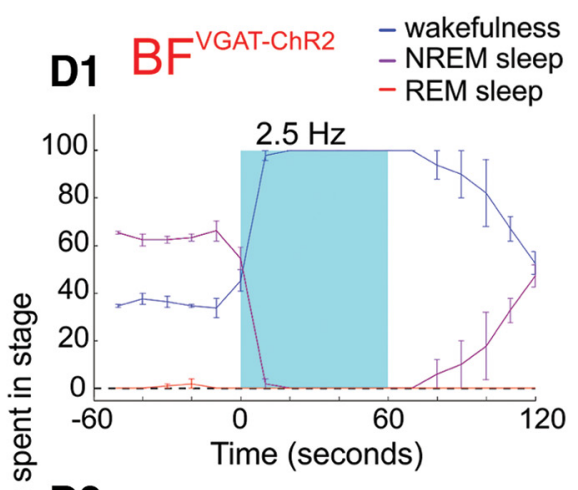

$10 \mathrm{~Hz}$

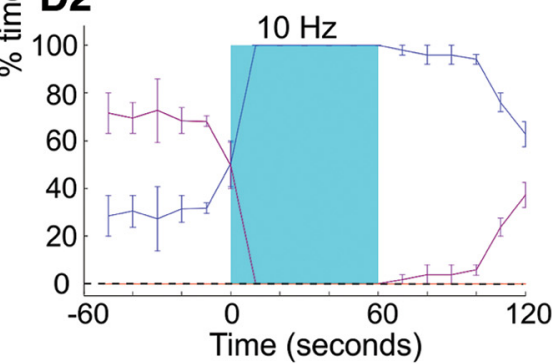

Figure 4. Absence of sleep-wake changes following optogenetic activation of $\mathrm{BF}^{\mathrm{SOM}}$ neurons. $\boldsymbol{A}$, Schematic showing experimental setup. B1, B2, Histological verification of ChR2-mCherryexpressing neurons within the BF (red), together with optical fiber placement $\left(^{*}\right)$ in both a BF ${ }^{\mathrm{SOM}-\mathrm{ChR2}}$ (B1) and BF ${ }^{\mathrm{VGAT}-\mathrm{ChR2}}$ (B2) mouse. Scale bar, $200 \mu \mathrm{m}$. C1, C2, Arousal state probability plots from BF ${ }^{\text {SOM-ChR2 }}$ mice showing wakefulness (blue), NREM sleep (purple), and REM sleep (red) over time as a percentage of the total number of trials over all mice $(n=7)$ before, during, and after blue light stimulation (light blue box) at either $2.5 \mathrm{~Hz}(\mathbf{C 1})$ or $10 \mathrm{~Hz}$ (C2). D1, D2, Arousal state probability plots from BF VGAT-ChR2 mice showing wakefulness (blue), NREM sleep (purple), and REM sleep (red) over time as a percentage of the total number of trials over all mice $(n=2)$ before, during, and after blue light stimulation (light blue box) at either $2.5 \mathrm{~Hz}(\mathbf{D} 1)$ or $10 \mathrm{~Hz}(\mathbf{D 2})$.

ANOVA, $\left.F_{(1,112)}=9.25, p=0.0029\right)$, and the numbers of REM sleep episode lasting 1-2.5 min were significantly decreased $(0.9 \pm 0.3$ vs $2.0 \pm 0.5$ episodes in control mice; $p<0.05$, Bonferroni's adjustment for multiple comparisons; Fig. 6A3).

Power spectral analysis revealed a similar power distribution in $\mathrm{BF}^{\text {SOM-DTA }}$ mice compared with control mice, during the beginning of the dark period, indicating that the increase in wakefulness amount was not associated with the EEG power change. During the light period, delta band power was decreased during the waking state $(26.7 \pm 0.8 \%$ vs $28.5 \pm 1.0 \%$ of total power in control mice; $p<0.05$, Bonferroni's adjustment for multiple comparisons). At the same time, REM sleep theta power was significantly increased $(44.5 \pm 1.3 \%$ vs $42.5 \pm 1.6 \%$ of total power in control mice; $p<0.05$, Bonferroni's adjustment for multiple comparisons; Fig. $6 C-D$ ).

Thus, beyond a decrease in cortical delta power during wakefulness and an increase in theta power during REM sleep, cortical EEG delta power was not significantly changed during NREM sleep in BF ${ }^{\text {SOM-DTA }}$ mice, indicating that these neurons are not involved in NREM sleep homeostatic control.

\section{Genotype comparisons}

As previous studies using this same SOM-ires-Cre mouse line have not, to our knowledge, evaluated potential sleep-wake phenotypic differences between heterozygous and homozygous SOM-ires-cre mice, we decided to compare baseline sleep-wake and EEG between homozygous SOM-ires-Cre and heterozygous SOM-ires-Cre (i.e., SOM-ires-Cre,lox-L10GFP) mice. To enable a more direct comparison with our chemogenetic and optogenetic work, we used homozygous and heterozygous SOM-ires-Cre mice with bilateral injections of AAVs targeting $\mathrm{BF}^{\mathrm{SOM}}$ neurons (hM3Dq-AAV and hM4Di-AAV or mCherry-AAV, respectively). Baseline recordings (i.e., in the absence of $\mathrm{CNO}$ ) revealed that homozygous SOM-ires-Cre mice exhibited significantly more NREM sleep, at the expense of wakefulness (Fig. 7B1), during the light period than heterozygous SOM-ires-Cre mice $(62.2 \pm 1.6 \%$ vs $54.5 \pm 1.2 \%$ of the light period; $p<0.01)$ and was associated with an increase in NREM sleep delta power $(42.9 \pm 0.7 \%$ vs $40.7 \pm$ $1.3 \%$ of total power; $p<0.05$; Fig. 7E2), suggesting elevated sleep pressure in the homozygous condition. Interestingly, REM sleep amount was significantly decreased during the dark period (3.0 \pm $0.3 \%$ vs $4.5 \pm 0.3 \%$ of the dark period, $p<0.05$; Fig. $7 D 1)$ in homozygous SOM-ires-Cre mice. Given that SOM-ires-Cre mice were obtained as homozygous breeders, the introduction of another strain (lox-L10GFP) was necessary to generate the heterozygous condition, and this could account in part or fully for the noted differences. Regardless, the possibility of a hypomorphic allele cannot be definitively ruled out in the homozygous condition and hence interpretative caution using this mouse line in the homozygous state is warranted.

\section{Discussion}

Results from our targeted activation (chemogenetic and optogenetic) and inhibition (chemogenetic) studies reveal that $\mathrm{BF}^{\mathrm{SOM}}$ neurons, presumably comprising both electrophysiologically identified subpopulations (Fig. 1), are neither sufficient nor necessary to appreciably and acutely alter the levels of behavioral or EEG wake or sleep. By contrast, our genetically driven deletion studies suggest that $\mathrm{BF}^{\mathrm{SOM}}$ neurons may influence the magnitude of waking as well as total REM sleep time during the early active period. Our data also suggest, but do not confirm, that the SOM-ires-Cre allele may be hypomorphic, biasing increased sleep in the homozygous condition. Together with previous work showing that optogenetic activation of $\mathrm{BF}^{\mathrm{SOM}}$ neurons during the inactive period (ZT4 to ZT8) increased the probability of a wake-NREM sleep transition, and that only a minority of $\mathrm{BF}^{\mathrm{SOM}}$ neurons $(\sim 22 \%$ of 
A

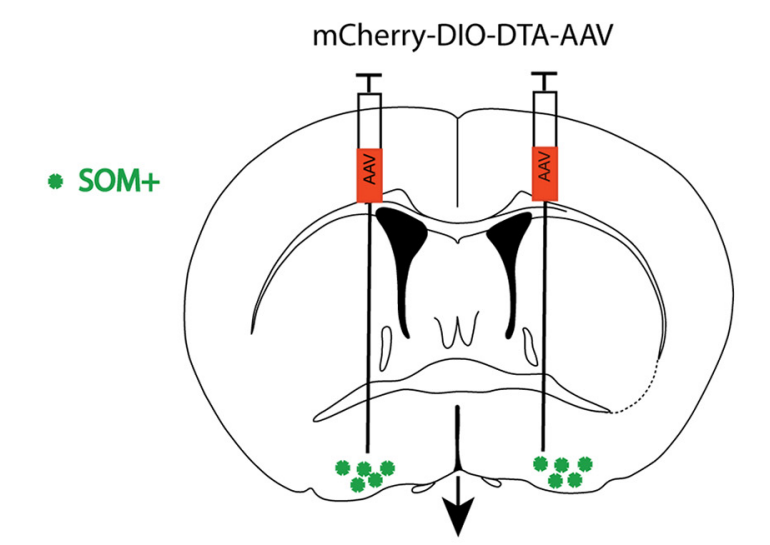

B

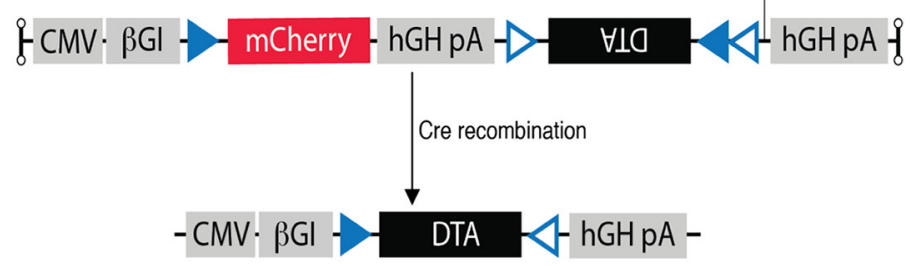

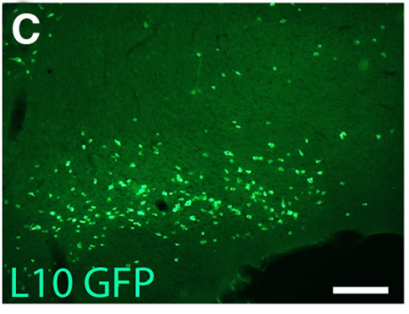

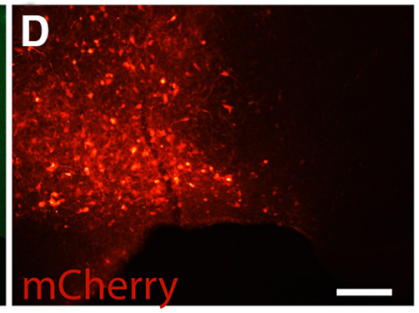

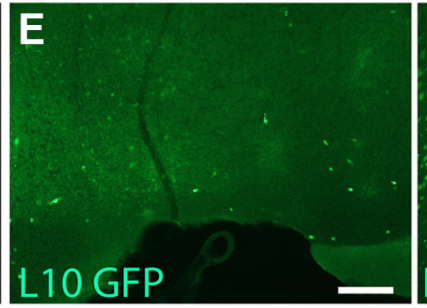

NREM Sleep
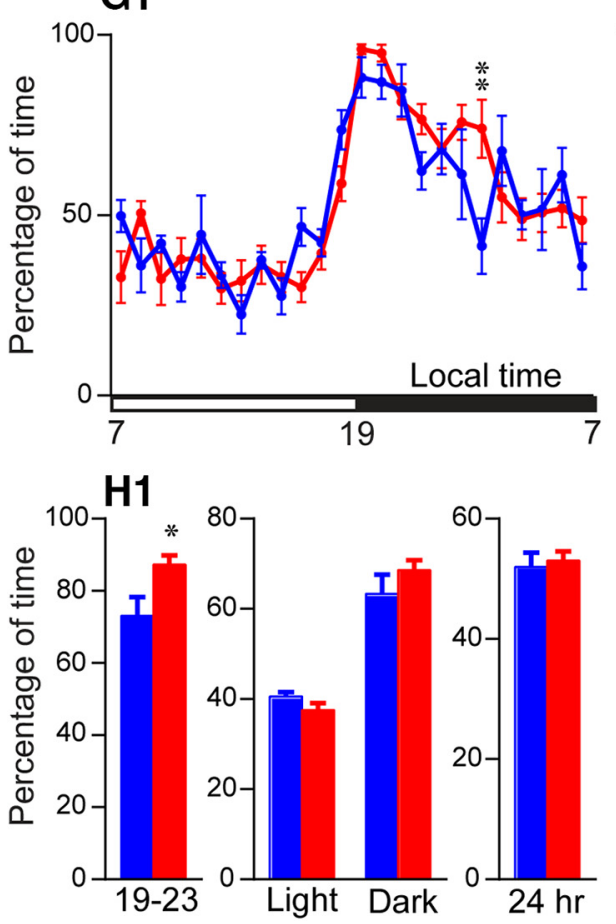

G2
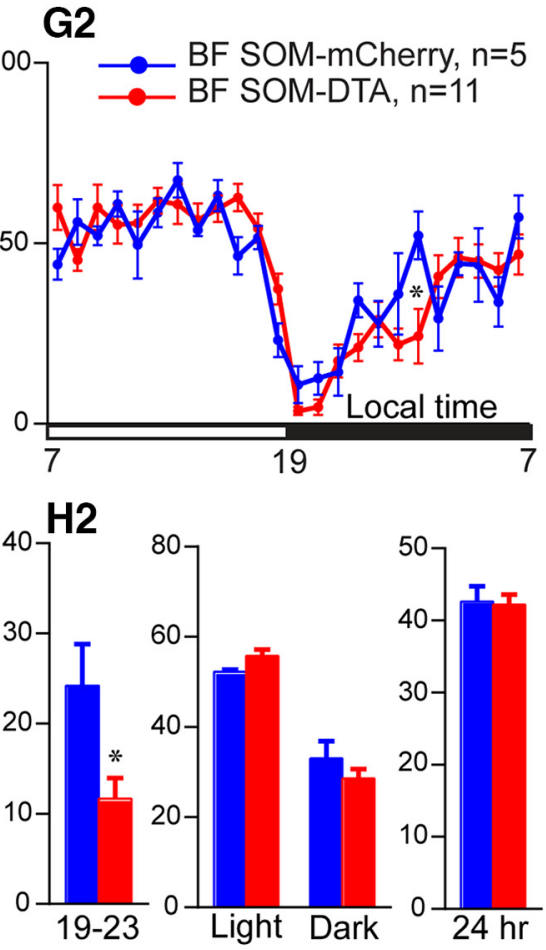

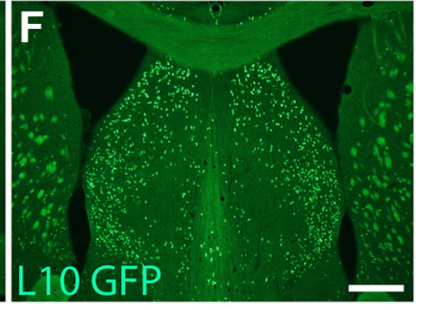

REM Sleep

G3

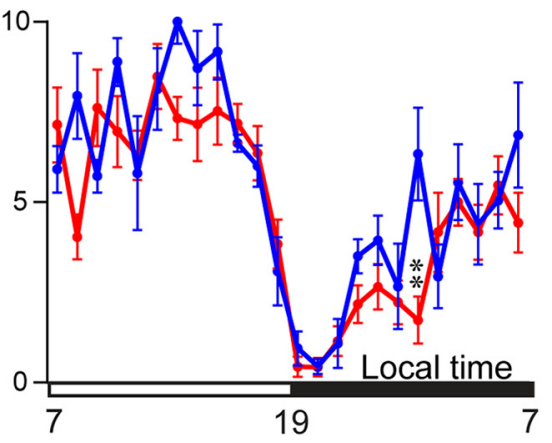

H3

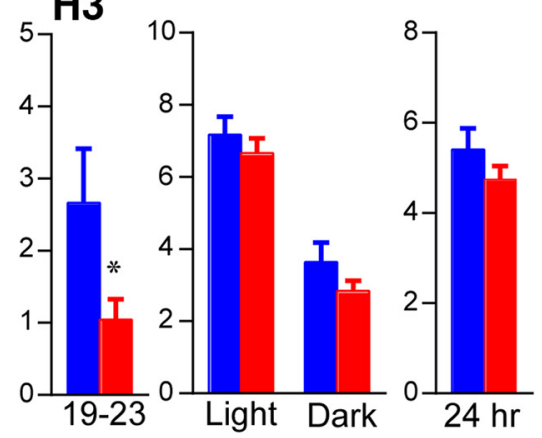

Figure 5. Sleep-wake quantitative changes following selective ablation of $B F^{S O M}$ neurons. $A$, Schematic showing experimental design. $B$, Cartoon of construct expressing the cellular toxin DTA in a cre-dependent configuration (NB mCherry is expressed in transfected cre-negative cells). C, SOM ${ }^{+}$neurons of the BF of the SOM-ires-cre,lox-L10GFP mouse. D, Injection of DTA-AAV into BF of SOM-ires-cre, lox-L10GFP mouse; red neurons show extent of cellular transfection and label surviving cells. $\boldsymbol{E}$, A corresponding section from the same mouse shown in $\boldsymbol{D}$ showing a nearly complete loss of SOM (green) cells following DTA-driven ablation. $F$, the dorsally situated lateral septum, which contains a large number of SOM ${ }^{+}$cells, was unaffected by the DTA-AAV targeting the BF (same mouse as $\boldsymbol{E}$; scale bar $\boldsymbol{C}-\boldsymbol{E}, 200 \mu \mathrm{m} ; \boldsymbol{F}, 400 \mu \mathrm{m}$ ). $\mathbf{G}$, Hourly amount ( \pm SEM) of wakefulness (W; $\mathbf{G 1}$ ), NREM sleep (NREMS; G2) and REM sleep (REMS; G3) in BF ${ }^{\text {SOM-DTA }}$ and control mouse groups $(n=$ 11 and 5 mice, respectively). $\boldsymbol{H}$, Amount ( \pm SEM) of the vigilance stages during the first $4 \mathrm{~h}$ of the dark period ( $19-23$ stages), during the light, dark, and $24 \mathrm{~h}$ periods in BF SOM-DTA and control mouse groups ( $n=11$ and 5 mice, respectively). ${ }^{*} p<0.05,{ }^{* *} p<0.01$, two-way ANOVA followed by a post hoc Bonferroni test (hourly amounts and light/dark analysis) or paired $t$ test (19-23 and $24 \mathrm{~h}$ ). 

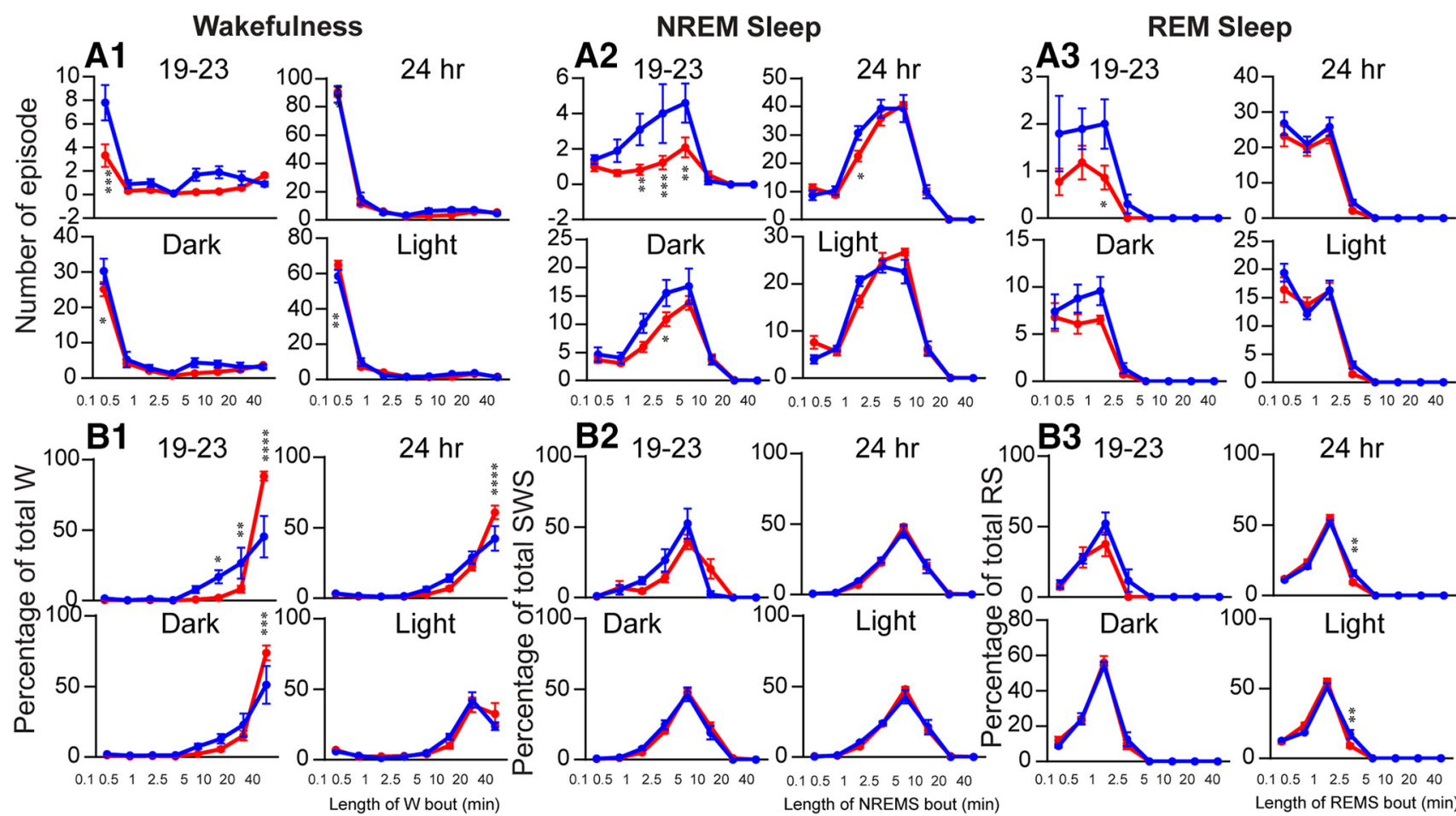

B2 $\left.19-23 \quad{ }^{100}\right] \quad 24 \mathrm{hr}$

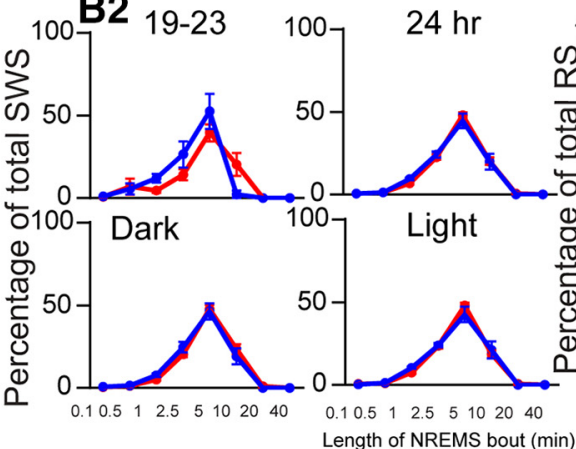

B3
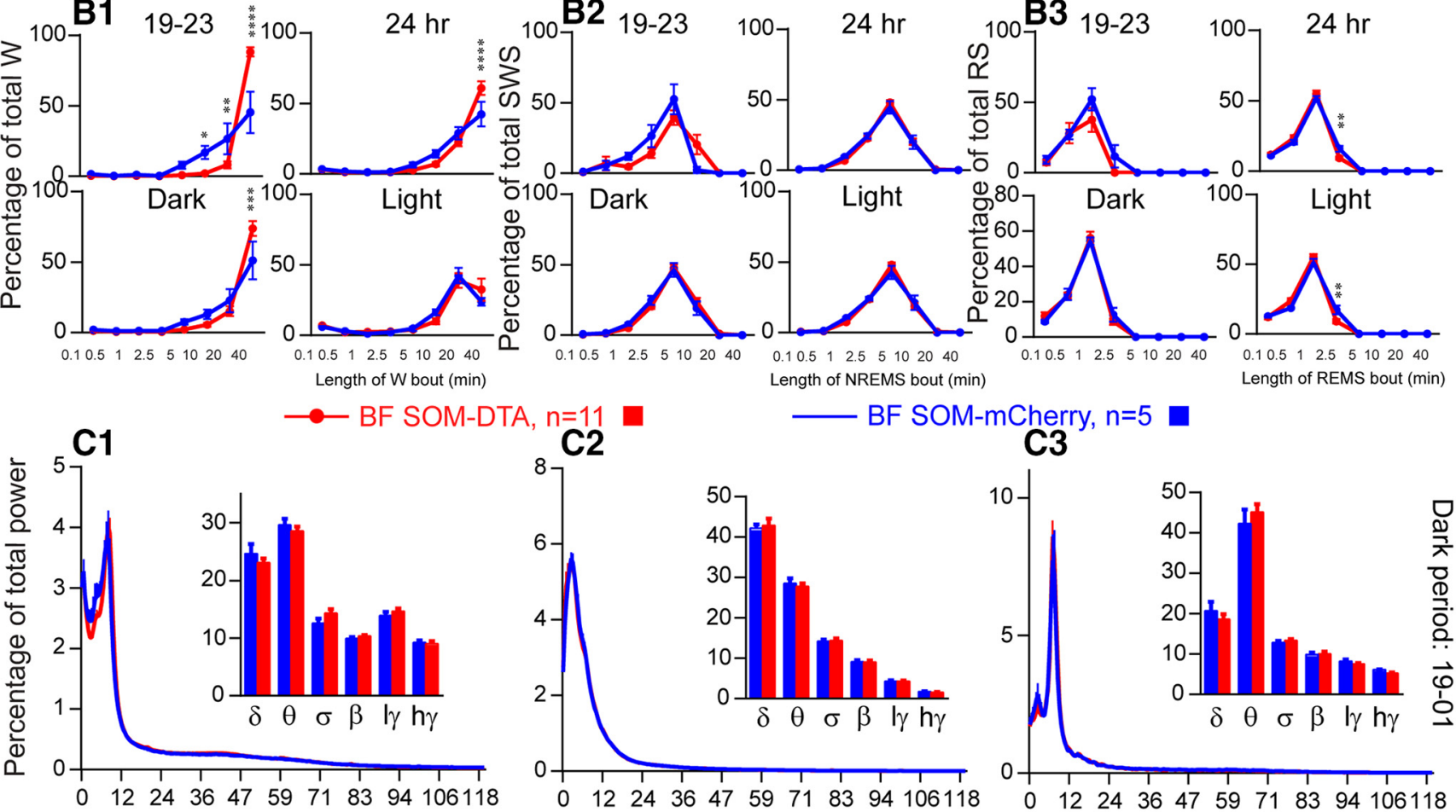

C3 3 , $n=5$
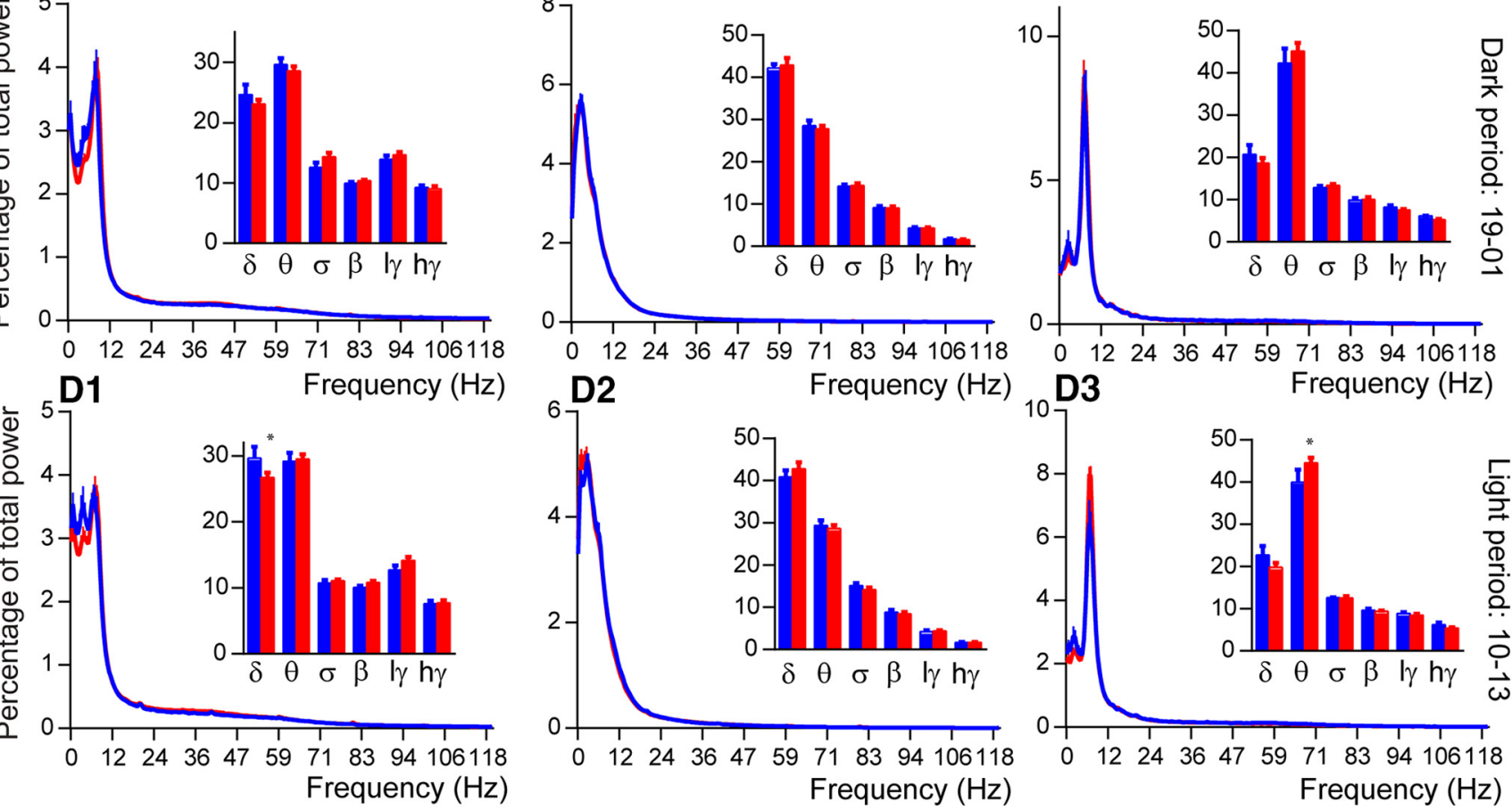

Figure 6. Sleep-wake qualitative changes following selective ablation of $B F{ }^{\mathrm{SOM}}$ neurons. $\boldsymbol{A}, \boldsymbol{B}$, Number of episodes ( \pm SEM) of wakefulness (W; $\left.\boldsymbol{A} \mathbf{1}, \boldsymbol{B} 1\right)$, NREM sleep (NREMS, $\boldsymbol{A 2}$, B2), or REM sleep (REMS, $A 3, B 3$ ) in each bout length $(\boldsymbol{A})$ and time-weighted frequency histograms $(\boldsymbol{B})$ showing the proportion ( \pm SEM) of W, NREMS, or REMS amounts in each bout length to the total amount of W, NREMS, or REMS during the first $4 \mathrm{~h}$ of the dark period (19-23), during the light, dark, and $24 \mathrm{~h}$ periods in $\mathrm{BF}^{\text {SOM-DTA }}$ and control mouse groups $\left(n=11\right.$ and 5 mice, respectively). ${ }^{*} p<0.05$, ${ }^{* *} p<0.01,{ }^{* * *} p<0.001,{ }^{* * * *} p<0.0001$, two-way ANOVA followed by a post hoc Bonferroni test. C, D, Power spectrum ( \pm SEM) over total power during the dark period (19-01; $\boldsymbol{C}$ ) and the light period $(10-13 ; \boldsymbol{D})$ and the power band ( \pm SEM) for the delta $(\delta, 0.5-5 \mathrm{~Hz})$, theta $(\theta, 5-9 \mathrm{~Hz})$, sigma $(\sigma, 9-15 \mathrm{~Hz})$, beta $(\beta, 15-30 \mathrm{~Hz})$, low-gamma $(l \gamma, 30-60 \mathrm{~Hz})$, and high-gamma $(\mathrm{h} \gamma, 60-120$ $\mathrm{Hz}$ ) frequency bands in $\mathrm{BF}^{\mathrm{SOM}-\mathrm{DTA}}$ and control mouse groups $\left(n=8\right.$ and 5 mice, respectively). ${ }^{* *} p<0.01,{ }^{* * *} p<0.001,{ }^{* * * *} p<0.0001$, two-way ANOVA followed by a post hoc Bonferroni test.

those recorded) were NREM active (Xu et al., 2015), we would propose a more nuanced and time-of-day-dependent role for $\mathrm{BF}^{\mathrm{SOM}}$ neurons in behavioral state control. Specifically, our data suggest that $\mathrm{BF}^{\mathrm{SOM}}$ neurons are not NREM sleep-, REM sleep-, or wake-promoting per se, but may exert, in particular during the early active period, a modest inhibitory influence on arousal circuitry, including possibly on local wake-promoting cells within the $\mathrm{BF}$. While it is unclear what the functional significance of this 
Wakefulness

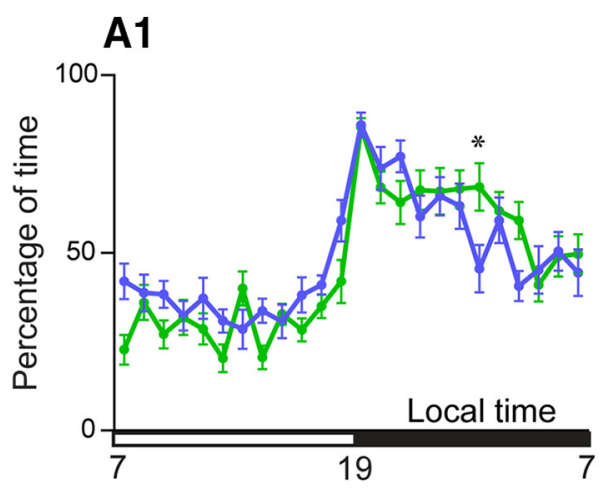

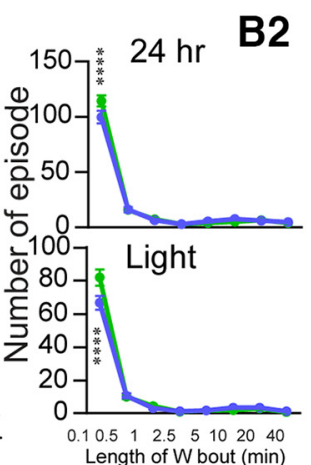

E1

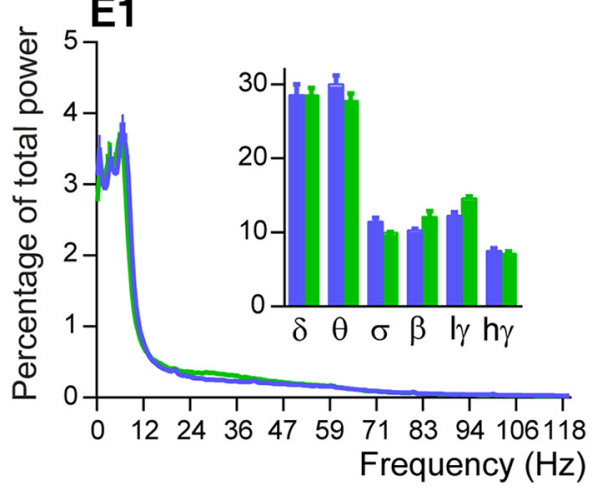

NREM Sleep

A2

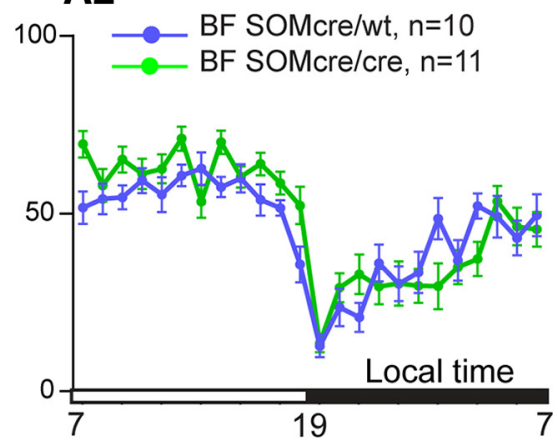

A3

REM Sleep
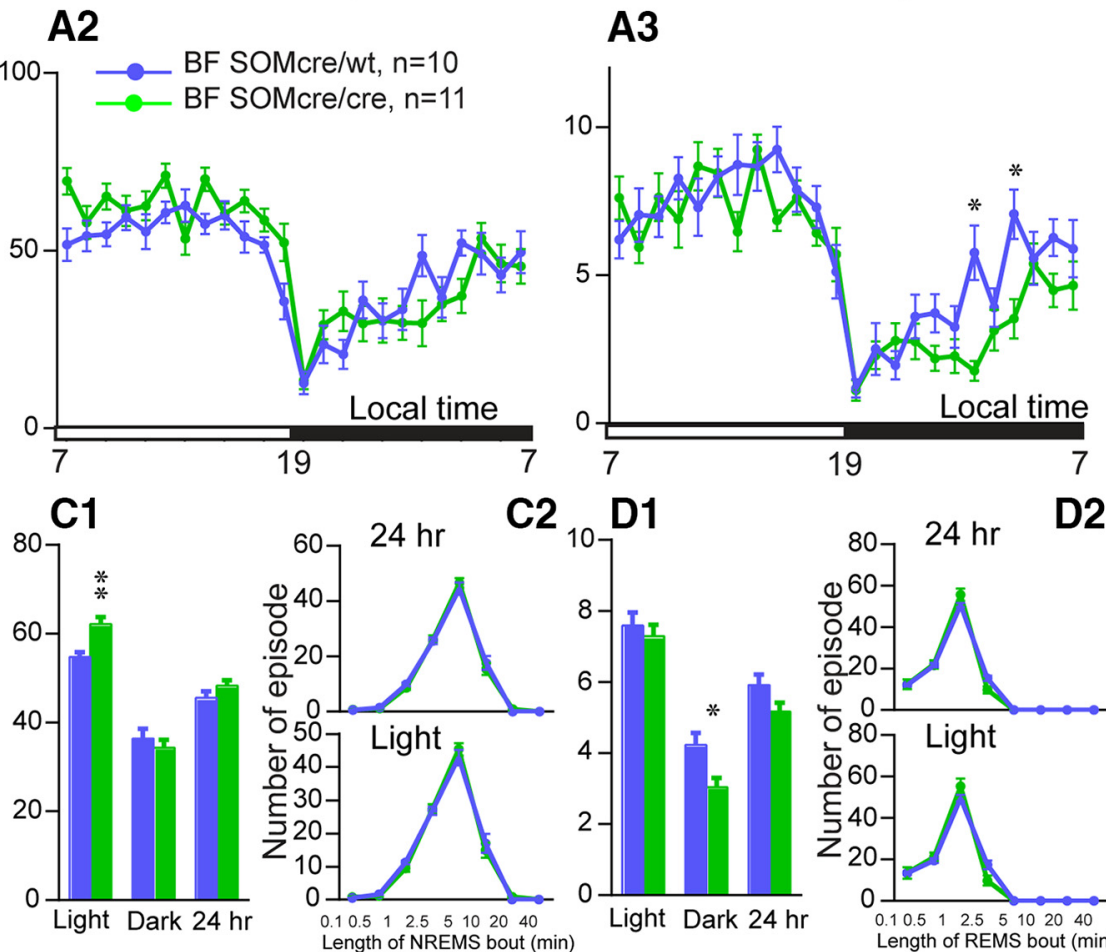

E2

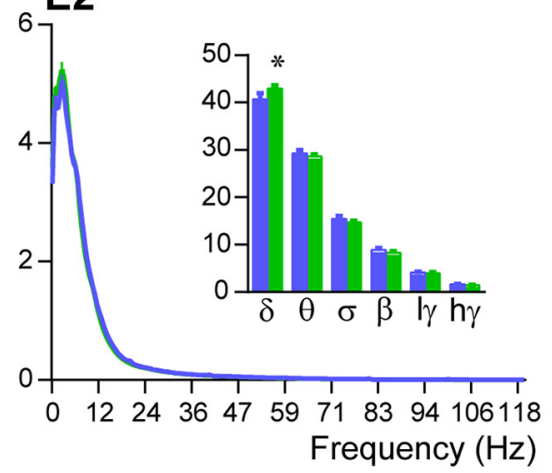

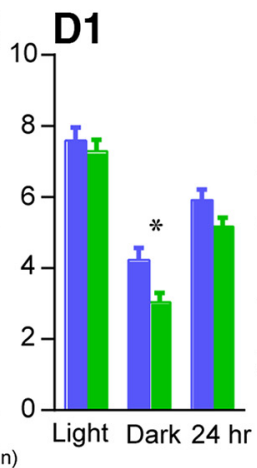

E3

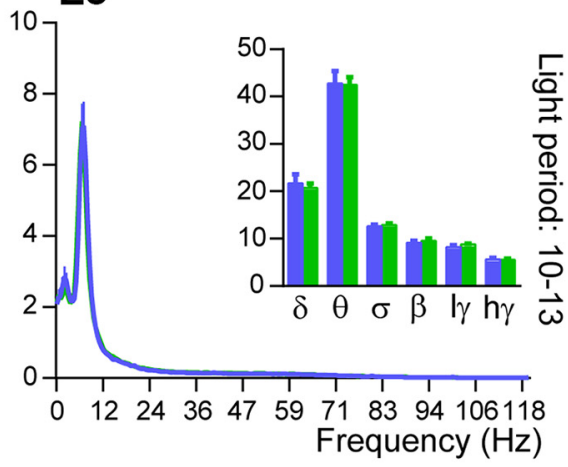

Figure 7. SOM-IRES-cre: a hypomorphic allele? A, Comparison of hourly amounts ( \pm SEM) of baseline wakefulness (W; $\boldsymbol{A} 1$ ), NREM sleep (NREMS; $A$ 2) and REM sleep (REMS; $\boldsymbol{A 3}$ ) in BF ${ }^{\text {SOMcre/cre }}$ (homozygous for the Cre allele, $n=11$ mice) and BF ${ }^{\text {SOMcre/wt }}$ (heterozygous for the Cre allele, $n=10$ mice) mouse groups. B1, C1, D1, Amount ( \pm SEM) of the vigilance stages during the light, dark, and $24 \mathrm{~h}$ baseline periods in $\mathrm{BF}^{\mathrm{SOMcre} / \mathrm{cre}}$ compared with $\mathrm{BF}{ }^{\text {SOMcre/wt }}$ mouse groups $\left(n=11\right.$ and 10 mice, respectively). ${ }^{*} p<0.05,{ }^{* *} p<0.01$, two-way ANOVA followed by a post hoc Bonferroni test (hourly amounts and light/dark analysis) or paired ttest (24h). B2, C2, D2, Number of episode ( \pm SEM) of wakefulness (W), NREM sleep (NREMS), or REM sleep (REMS) in each bout length during the light and $24 \mathrm{~h}$ periods in $\mathrm{BF}{ }^{\text {SOMcre/cre }}$ compared with $\mathrm{BF}^{\text {SOMcre/wt }}$ mouse groups $\left(n=11\right.$ and 10 mice, respectively). ${ }^{* *} p<0.01,{ }^{* * * *} p<0.0001$, two-way ANOVA followed by a post hoc Bonferroni test. E1, E2 and E3, Power spectrum ( \pm SEM) over total power during the dark period $(19-01)$ and power band $( \pm S E M)$ for the delta $(\delta, 0.5-5 \mathrm{~Hz})$, theta $(\theta, 5-9 \mathrm{~Hz})$, sigma $(\sigma, 9-15$ $\mathrm{Hz})$, beta $(\beta, 15-30 \mathrm{~Hz})$, low-gamma $(\mathrm{l} \gamma, 30-60 \mathrm{~Hz})$, and high-gamma $(\mathrm{h} \gamma, 60-120 \mathrm{~Hz})$ frequency bands, in $\mathrm{BF}^{\text {somcre/cre }}$ compared with $\mathrm{BF}^{\text {50Mcre/wt }}$ mouse groups $(n=8$ and 9 mice, respectively). ${ }^{*} p<0.05,{ }^{* * *} p<0.0001$, two-way ANOVA followed by a post hoc Bonferroni test.

"dampening" effect of $\mathrm{BF}^{\mathrm{SOM}}$ neurons on active period waking levels might be, one possibility is that they may help fine tune the level of behavioral arousal, likely via modulation of neighboring BF cholinergic and GABAergic neurons, in accordance with situational-specific cognitive demands. To this end, $\mathrm{BF}^{\mathrm{SOM}}$ neurons directly inhibit, via the release of GABA, BF wake-promoting cells, including cholinergic cells (Xu et al., 2015), the activity of which is strongly linked to many cognitive processes (Gielow and Zaborszky, 2017). The time of day of this influence on wakefulness levels observed in our study would also suggest that the operative population of $\mathrm{BF}^{\mathrm{SOM}}$ neurons is wake active, and not sleep active.

\section{The cellular BF and wakefulness}

Pharmacologic, lesion, stimulation, chemogenetic, and optogenetic studies have established a key role for the BF in electrocor- tical and behavioral arousal. For example, direct stimulation of the BF has pronounced activating effects on the cortical EEG (Berridge and Foote, 1996; Cape and Jones, 2000), whereas lesions of the BF increase EEG delta activity, reduce wakefulness, or result in low-amplitude EEG and behavioral unresponsiveness (Buzsaki et al., 1988; Fuller et al., 2011; Kaur et al., 2013). Recent studies, including from our laboratory, have attempted to genetically parse the contribution of individual BF cell populations, including cholinergic, glutamatergic, and GABAergic cell groups, in these processes (Anaclet et al., 2015; Kim et al., 2015; Xu et al., 2015; Yang et al., 2017). For example, optogenetic studies of the cholinergic BF cell group have indicated that these cell groups (1) promotes both wakefulness and REM sleep or (2) just wakefulness. In some contrast, two chemogenetic-based studies showed that acute activation of BF cholinergic neurons led to fragmentation 
of the sleep state and suppressed lower-frequency EEG components during NREM sleep, but was not wake-promoting per se (Anaclet et al., 2015; Chen et al., 2016). With respect to the glutamatergic BF cell group, it was recently reported that optogenetic stimulation of glutamatergic BF neurons potently drove wakefulness from NREM sleep (Xu et al., 2015). Once again in some contrast, chemogenetic activation of this same cell group had no effect on sleep latency or consolidation and produced no changes in the EMG or EEG fast frequencies, but did result in a small decrease in EEG delta power during NREM sleep, indicating a contribution to cortical desynchronization (Anaclet et al., 2015). Finally, investigations of the GABAergic BF cell population have revealed, consistently, strong high-frequency EEG- and wake-promoting responses (Anaclet et al., 2015; Kim et al., 2015). In the first of the optogenetic-based studies, the authors found that stimulation of parvalbumin-containing GABAergic BF $\left(\mathrm{BF}^{\text {Parv }}\right)$ neurons elicited cortical gamma band oscillations (GBOs; $\sim 40 \mathrm{~Hz}$ activity), linking their activation to higher cognitive function (Kim et al., 2015). In a second published optogenetic study, the authors found that optogenetic stimulation of $\mathrm{BF}^{\text {Parv }}$ neurons elicits waking, but not GBO (Xu et al., 2015). Finally, in a contemporaneous chemogenetic study we found that acute activation of GABAergic BF neurons ( $\mathrm{BF}^{\mathrm{VGAT}}$ ) neurons potently drove wakefulness as well as high-gamma $(60-120 \mathrm{~Hz})$ EEG activity (Anaclet et al., 2015). We further showed that acute inhibition of $\mathrm{BF}^{\mathrm{VGAT}}$ neurons during the early dark period, a typical time of maximal wakefulness in the mouse, resulted in a significant decrease in behavioral wakefulness, establishing the necessity of $\mathrm{BF}^{\mathrm{VGAT}}$ neurons for wakefulness maintenance (Anaclet et al., 2015). These rather monolithic waking/EEG activating responses seen following the activation of $\mathrm{BF}^{\mathrm{VGAT}}$ neurons belie the functional and anatomic complexity of the GABAergic BF cell population, namely the existence of wake-, REM-, and NREM sleep-active subgroups as well as subgroups that contain different calcium-binding proteins, such as parvalbumin, calbindin-D28k, and calretinin, or other markers, including the SOM cell group investigated in the present study (Yang et al., 2017).

\section{The cellular BF and sleep}

Older literature has suggested that the BF may contain, in addition to wake-promoting cell populations, NREM sleep-promoting circuitry. For example, the BF contains sleep-active cells (Hassani et al., 2009; Sakai, 2011; Xu et al., 2015), and lesions placed into the $\mathrm{BF}$ of the cat have been reported to increase EEG and behavioral waking, presumably secondary to the loss of NREM sleep-promoting neurons (McGinty and Sterman, 1968; Szymusiak and McGinty, 1986). As indicated, a recent optogenetic study revealed a NREM sleep-promoting role for BF ${ }^{\text {SOM }}$ neurons (Xu et al., 2015), suggesting the cellular basis for these wake-promoting lesions. This finding is, however, difficult to reconcile with the outcomes from our activation, inhibition, and lesion experiments, which were inconsistent with $\mathrm{BF}^{\mathrm{SOM}}$ neurons promoting NREM sleep per se. In fact, the results of our chemogenetic studies, which used the same vector system and construct as used in our previous studies to activate BF ${ }^{\text {VGAT }}$ (Anaclet et al., 2015), lateral hypothalamic $\mathrm{VGAT}^{+}$(Venner et al., 2016), and supramammillary (Pedersen et al., 2017) or parafacial VGAT ${ }^{+}$(Anaclet et al., 2014, 2018) neurons (potently driving wakefulness or sleep), were acutely underwhelming in this regard. While these disparate outcomes could link to some unrecognized technical difference, we feel that a critical reassessment of the articles using lesions cited in support of the concept that the BF contains NREM sleep-promoting circuitry may be particular revealing. Specifically, a review of the lesion maps shown in these articles suggest that the lesions themselves may have included, in part or entirety, the ventrolateral preoptic nucleus (VLPO). The VLPO comprises a major NREM sleep-promoting cell population within the preoptic forebrain (Sherin et al., 1996; Lu et al., 2000), and in the cat the VLPO is located laterally adjacent to the BF (Gaus et al., 2002), and hence, far more lateral from the midline than in the rodent. At the time that these lesion studies were published the VLPO had not yet been identified, and as such the authors of the articles had no a priori reason to assume that the lesions might have encroached upon this NREM sleep-promoting cell group. Hence, and until shown otherwise, we feel that a more parsimonious explanation for the increased wakefulness observed in the BF-lesioned cats is unintended ablation of the NREM sleep-promoting VLPO, and not disruption/ablation of a resident NREM sleep-promoting cell group (but see limitations below).

\section{Limitations}

Two technical points must be considered when interpreting our data. First, in light of the revealed electrophysiological heterogeneity in the present study and the variable state-dependent activity of $\mathrm{BF}^{\mathrm{SOM}}$ neurons demonstrated by another group (Xu et al., 2015), it is possible, if not likely, that different subpopulations of $\mathrm{BF}^{\mathrm{SOM}}$ neurons subserve different aspects of behavioral state control. As these putative subsets of $\mathrm{BF}^{\mathrm{SOM}}$ neurons have not, to our knowledge, been molecularly defined, the ability to selectively target $\mathrm{BF}^{\mathrm{SOM}}$ subpopulations is constrained. Hence, the changes observed in our measured response variables reflect presumptive concurrent manipulation of all $\mathrm{BF}^{\mathrm{SOM}}$ subpopulations, and we therefore cannot rule out the possibility that, for example, the manipulation of one subpopulation may antagonize the activity of the other subpopulations. What is clear from our experimental work is that the influence of $\mathrm{BF}^{\mathrm{SOM}}$ on wakefulness, NREM sleep, and REM sleep, both in the acute and chronic conditions, are modest across interrogations and likely dependent on time of day.

The second consideration is that while the SOM-ires-Cre was designed as a $3^{\prime}$ knockin, our comparison of the heterozygous versus homozygous condition suggests that it may be a hypomorphic allele. While we could not definitely conclude this on the basis of our comparison, which included the introduction of a different strain of mouse, we did find that homozygous SOM-cre mice exhibited slightly more NREM sleep during the light period and across the $24 \mathrm{~h}$ day than heterozygous SOM-cre mice. The increase in NREM sleep in the homozygous condition was largely attributable to an increase in the number of 2.5-5 min NREM sleep episodes. Thus, on the one hand, the increases in total NREM sleep and 2.5-5 min NREM sleep episodes would actually suggest, in the context of a hypomorphic allele, that SOM-cre neurons are modestly wakefulness promoting, and not sleep promoting. On the other hand, our acute activation and inhibition studies would suggest that the modulation of $\mathrm{BF}^{\mathrm{SOM}}$ neurons is not sufficient to appreciably or acutely alter sleep or wakefulness, whereas our ablation studies suggest that $\mathrm{BF}^{\mathrm{SOM}}$ neurons may exert a modest inhibitory influence on waking during the early active period, an effect that is likely mediated by GABA release since this effect on waking was not observed in the nonablated, homozygous mice in which GABA production and release is unlikely affected. Additionally, our in vitro data, together with previous optrode data (Xu et al., 2015), suggest considerable heterogeneity in the $\mathrm{BF}^{\mathrm{SOM}}$ population, which would be consistent with the diversity of modest influences that these neurons appear to exert on behavioral states. 


\section{Conclusions}

Our experimental outcomes suggest a modest and time-of-daydependent influence of $\mathrm{BF}^{\mathrm{SOM}}$ neurons on behavioral state and are generally inconsistent with the idea that this cell population is NREM sleep promoting, as was previously proposed. Together with previous work on the cellular BF, the findings from the present study not only emphasize strong functional heterogeneity across $\mathrm{BF}^{\mathrm{VGAT}}$ subgroups, but also point to $\mathrm{BF}^{\text {Parv }}$ neurons as being uniquely wake promoting among the subgroups of $\mathrm{BF}^{\mathrm{VGAT}}$ cell populations thus far tested. Also, our lesion findings in particular suggest the interesting possibility that impairment of $\mathrm{BF}^{\mathrm{SOM}}$ neurons may contribute, at least in part, to hyperarousal phenotypes (e.g., hyperarousal of post-traumatic stress disorder). Future studies interrogating other $\mathrm{BF}^{\mathrm{VGAT}}$ subgroups as well as defining the circuit basis by which they regulate behavioral states are eagerly awaited.

\section{References}

Alexander GM, Rogan SC, Abbas AI, Armbruster BN, Pei Y, Allen JA, Nonneman RJ, Hartmann J, Moy SS, Nicolelis MA, McNamara JO, Roth BL (2009) Remote control of neuronal activity in transgenic mice expressing evolved G protein-coupled receptors. Neuron 63:27-39. CrossRef Medline

Anaclet C, Ferrari L, Arrigoni E, Bass CE, Saper CB, Lu J, Fuller PM (2014) The GABAergic parafacial zone is a medullary slow wave sleep-promoting center. Nat Neurosci 17:1217-1224. CrossRef Medline

Anaclet C, Pedersen NP, Ferrari LL, Venner A, Bass CE, Arrigoni E, Fuller PM (2015) Basal forebrain control of wakefulness and cortical rhythms. Nat Commun 6:8744. CrossRef Medline

Anaclet C, Griffith K, Fuller PM (2018) Activation of the GABAergic parafacial zone maintains sleep and counteracts the wake-promoting action of the psychostimulants armodafinil and caffeine. Neuropsychopharmacology 43:415-425. CrossRef Medline

Berridge CW, Foote SL (1996) Enhancement of behavioral and electroencephalographic indices of waking following stimulation of noradrenergic beta-receptors within the medial septal region of the basal forebrain. J Neurosci 16:6999-7009. CrossRef Medline

Buzsaki G, Bickford RG, Ponomareff G, Thal LJ, Mandel R, Gage FH (1988) Nucleus basalis and thalamic control of neocortical activity in the freely moving rat. J Neurosci 8:4007-4026. CrossRef Medline

Cape EG, Jones BE (2000) Effects of glutamate agonist versus procaine microinjections into the basal forebrain cholinergic cell area upon gamma and theta EEG activity and sleep-wake state. Eur J Neurosci 12:21662184. CrossRef Medline

Chen L, Yin D, Wang TX, Guo W, Dong H, Xu Q, Luo YJ, Cherasse Y, Lazarus M, Qiu ZL, Lu J, Qu WM, Huang ZL (2016) Basal forebrain cholinergic neurons primarily contribute to inhibition of electroencephalogram delta activity, rather than inducing behavioral wakefulness in mice. Neuropsychopharmacology 41:2133-2146. CrossRef Medline

De BP, Heguy A, Hackett NR, Ferris B, Leopold PL, Lee J, Pierre L, Gao G, Wilson JM, Crystal RG (2006) High levels of persistent expression of alphal-antitrypsin mediated by the nonhuman primate serotype rh.10 adeno-associated virus despite preexisting immunity to common human adeno-associated viruses. Mol Ther 13:67-76. CrossRef Medline

Fuller PM, Sherman D, Pedersen NP, Saper CB, Lu J (2011) Reassessment of the structural basis of the ascending arousal system. J Comp Neurol 519: 933-956. CrossRef Medline

Gao GP, Alvira MR, Wang L, Calcedo R, Johnston J, Wilson JM (2002) Novel adeno-associated viruses from rhesus monkeys as vectors for human gene therapy. Proc Natl Acad Sci U S A 99:11854-11859. CrossRef Medline

Gaus SE, Strecker RE, Tate BA, Parker RA, Saper CB (2002) Ventrolateral preoptic nucleus contains sleep-active, galaninergic neurons in multiple mammalian species. Neuroscience 115:285-294. CrossRef Medline

Gielow MR, Zaborszky L (2017) The input-output relationship of the cholinergic basal forebrain. Cell Rep 18:1817-1830. CrossRef Medline

Gomez JL, Bonaventura J, Lesniak W, Mathews WB, Sysa-Shah P, Rodriguez LA, Ellis RJ, Richie CT, Harvey BK, Dannals RF, Pomper MG, Bonci A, Michaelides M (2017) Chemogenetics revealed: DREADD occupancy and activation via converted clozapine. Science 357:503-507. CrossRef Medline

Hajdu I, Szentirmai E, Obal F Jr, Krueger JM (2003) Different brain structures mediate drinking and sleep suppression elicited by the somatostatin analog, octreotide, in rats. Brain Res 994:115-123. CrossRef Medline

Hassani OK, Lee MG, Henny P, Jones BE (2009) Discharge profiles of identified GABAergic in comparison to cholinergic and putative glutamatergic basal forebrain neurons across the sleep-wake cycle. J Neurosci 29: 11828-11840. CrossRef Medline

Hu H, Cavendish JZ, Agmon A (2013) Not all that glitters is gold: off-target recombination in the somatostatin-IRES-cre mouse line labels a subset of fast-spiking interneurons. Front Neural Circuits 7:195. CrossRef Medline

Kaur S, Pedersen NP, Yokota S, Hur EE, Fuller PM, Lazarus M, Chamberlin NL, Saper CB (2013) Glutamatergic signaling from the parabrachial nucleus plays a critical role in hypercapnic arousal. J Neurosci 33:7627-7640. CrossRef Medline

Kim T, Thankachan S, McKenna JT, McNally JM, Yang C, Choi JH, Chen L, Kocsis B, Deisseroth K, Strecker RE, Basheer R, Brown RE, McCarley RW (2015) Cortically projecting basal forebrain parvalbumin neurons regulate cortical gamma band oscillations. Proc Natl Acad Sci U S A 112:35353540. CrossRef Medline

Lu J, Greco MA, Shiromani P, Saper CB (2000) Effect of lesions of the ventrolateral preoptic nucleus on NREM and REM sleep. J Neurosci 20: 3830-3842. CrossRef Medline

McGinty DJ, Sterman MB (1968) Sleep suppression after basal forebrain lesions in the cat. Science 160:1253-1255. CrossRef Medline

Paxinos GT, Franklin K (2001) The mouse brain in stereotaxic coordinates, Ed 2. San Diego, CA: Academic.

Pedersen NP, Ferrari L, Venner A, Wang JL, Abbott SBG, Vujovic N, Arrigoni E, Saper CB, Fuller PM (2017) Supramammillary glutamate neurons are a key node of the arousal system. Nat Commun 8:1405. CrossRef Medline

Sakai K (2011) Sleep-waking discharge profiles of median preoptic and surrounding neurons in mice. Neuroscience 182:144-161. CrossRef Medline

Sherin JE, Shiromani PJ, McCarley RW, Saper CB (1996) Activation of ventrolateral preoptic neurons during sleep. Science 271:216-219. CrossRef Medline

Szymusiak R, McGinty D (1986) Sleep suppression following kainic acidinduced lesions of the basal forebrain. Exp Neurol 94:598-614. CrossRef Medline

Venner A, Anaclet C, Broadhurst RY, Saper CB, Fuller PM (2016) A novel population of wake-promoting GABAergic neurons in the ventral lateral hypothalamus. Curr Biol 26:2137-2143. CrossRef Medline

Xu M, Chung S, Zhang S, Zhong P, Ma C, Chang WC, Weissbourd B, Sakai N, Luo L, Nishino S, Dan Y (2015) Basal forebrain circuit for sleep-wake control. Nat Neurosci 18:1641-1647. CrossRef Medline

Yang C, Thankachan S, McCarley RW, Brown RE (2017) The menagerie of the basal forebrain: how many (neural) species are there, what do they look like, how do they behave and who talks to whom? Curr Opin Neurobiol 44:159-166. CrossRef Medline

Zhu C, Yao Y, Xiong Y, Cheng M, Chen J, Zhao R, Liao F, Shi R, Song S (2017) Somatostatin neurons in the basal forebrain promote highcalorie food intake. Cell Rep 20:112-123. CrossRef Medline

Ziegenbein M, Held K, Kuenzel HE, Murck H, Antonijevic IA, Steiger A (2004) The somatostatin analogue octreotide impairs sleep and decreases EEG sigma power in young male subjects. Neuropsychopharmacology 29:146-151. CrossRef Medline 